“The final publication is available at IOS Press through http://dx.doi.org/ $10.1088 / 1748-605 X / a a 62 b 0$

\title{
Bioamine-crosslinked gellan gum hydrogel for neural tissue
}

\section{engineering}

Janne T Koivisto ${ }^{1,2 *}$, Tiina Joki ${ }^{2}$, Jenny E Parraga ${ }^{1}$, Rami Pääkkönen ${ }^{2}$, Laura Ylä-Outinen ${ }^{2}$, Laura Salonen ${ }^{1}$, Ilari Jönkkäri ${ }^{3}$, Marja Peltola ${ }^{2}$,Teemu O Ihalainen ${ }^{2}$, Susanna Narkilahti ${ }^{2 * *}$, Minna

$$
\begin{gathered}
{\text { Kellomäki }{ }^{1,2 * *}}_{*}^{* \text { And } * *=\text { writers contributed equally }}
\end{gathered}
$$

1 BioMediTech - Biomedical Sciences and Engineering, Tampere University of Technology, Korkeakoulunkatu 3, 33720 Tampere, Finland

2 BioMediTech and Faculty of Medicine and Life Sciences, University of Tampere, Lääkärinkatu 1, 33520 Tampere, Finland

3 Laboratory of Materials Science, Tampere University of Technology, Korkeakoulunkatu 6, 33720 Tampere, Finland

Email: janne.t.koivisto@tut.fi, tiina.joki@uta.fi, susanna.narkilahti@uta.fi,minna.kellomaki@tut.fi 


\section{ABSTRACT:}

Neural tissue engineering and 3D in vitro tissue modeling require the development of biomaterials that take into account the specified requirements of human neural cells and tissue. In this study, an alternative method of producing biomimetic hydrogels based on gellan gum (GG) was developed by replacing traditional crosslinking methods with the bioamines spermidine and spermine. These bioamines were proven to function as crosslinkers for GG hydrogel at $+37^{\circ} \mathrm{C}$, allowing for the encapsulation of human neurons. We studied the mechanical and rheological properties of the formed hydrogels, which showed biomimicking properties comparable to naïve rabbit brain tissue under physiologically relevant stress and strain. Human pluripotent stem cell-derived neuronal cells demonstrated good cytocompatibility in the GG-based hydrogels. Moreover, functionalization of GG hydrogels with laminin resulted in cell type-specific behavior: neuronal cell maturation and neurite migration.

Submitted to Biomedical Materials. 


\section{Introduction}

Tissue engineering (TE) is a field of study that aims to produce tissue-like structures in vivo and in vitro using a combination of a biomaterial and living cells [1]. Thus, TE has combined advances in cell therapy and biomaterials science to stabilize an injury or defect site and deliver cells and molecules to promote the regeneration of damaged tissues $[1 ; 2]$. Neural TE has emerged as a promising strategy for neural regeneration, both for the central nervous system (CNS) and the peripheral nervous system, which suffer from limited regenerative capacity [2-4]. For successful functional neural TE graft, it is important to combine neural tissue mimicking material e.g. a hydrogel and clinically relevant human cell type [5]. In addition to therapeutic use in TE, hydrogels as neural scaffolds can also be used for in vitro disease modeling, drug testing and developmental biology studies [5-7].

The main requirement for biomaterials intended for TE is biocompatibility [3; 8; 9], defined by the International Union of Pure and Applied Chemistry (IUPAC) as "the ability to be in contact with a living system without producing an adverse effect" [9]. Hydrogel biomaterials can fulfill the biocompatibility (systemic scale) and cytocompatibility (cellular scale) requirements [8], and their tunable physical properties can mimic soft tissue, such as CNS [3-5]. Thus, while designing hydrogels for TE, important material characteristics to take into account are for example mechanical properties, porosity, permeability and transparency, especially for in vitro TE [4; 10-12]. Moreover, hydrogels can be further modified to incorporate extracellular matrix (ECM) molecules (such as collagen, fibronectin, and laminin) or peptides to provide anchoring sites for cells and to enhance growth $[3 ; 4 ; 11]$.

Gellan gum (GG) is an exopolysaccharide produced by Sphingomonas elodea bacteria. This biologically safe polymer has been approved by the Food and Drug Administration (FDA) and the European Medicines Agency (EMA) [13-15], and it has been recently been suggested as a material for scaffold development for TE [16; 17]. GG is a deacetylated form of gellan molecule which has a tetrasaccharide repeating structure of $\beta$-D-glucose, $\beta$-D-glucuronic acid and $\alpha$-L-rhamnose in a 2:1:1 ratio [13]. Like many other polysaccharides, GG is a relatively inert biomaterial [17]. To improve cell attachment, GG-based hydrogels have been functionalized with peptides by covalently binding them in 
the molecule backbone itself [17; 18]. GG has been studied for bone [16; 19], cartilage [20—22] and spinal cord [23-27] TE applications. In neural applications, GG can support the in vitro culture of rodent or human cells (neural stem cells [18; 28], olfactory ensheathing glia cells [18], oligodendrocyte-like cells [23]) and has been shown to be biocompatible in vivo in a hemisection rat spinal cord injury model [23].

GG hydrogels produced by physical, ionotropic, crosslinking with metallic cations $\left(\mathrm{Ca}^{2+}, \mathrm{Mg}^{2+}, \mathrm{Na}^{+}\right.$, $\mathrm{K}^{+}$) are primarily mechanically weak [13;29]. Another option is chemical crosslinking using methacrylate derivatives, followed by the addition of a photoinitiator and photocrosslinking with UVlight $[23 ; 29]$. Disadvantages of these crosslinking methods include cation leakage or exchange, weakening of the mechanical properties of the hydrogel over time [29; 30], phototoxicity of UV-light and chemical reactivity of the photoinitiator [31-33]. Chemical crosslinking is often in practice more complicated than ionotropic crosslinking. Bioamines spermine (SPM) and spermidine (SPD) are small cations that have been demonstrated to interact with anionic polymers such as GG [34-36]. Crosslinking with bioamines is simple, and a wide crosslinker concentration range can be applied to vary the mechanical properties of GG in a controlled way, so they provide an alternative crosslinking method. SPM and SPD are present in all living cells, and they play important roles in many physiological processes, such as protecting DNA by scavenging oxygen radicals and affecting cell proliferation [37; $38]$ also in neural cells $[39 ; 40]$.

In this study, we developed GG bioamine hydrogels with mechanical properties that resemble brain tissue. The resulting hydrogels were characterized mechanically and rheologically. The mechanical properties of these hydrogels were compared to naïve rabbit brain tissue by compression testing. Hydrogels with a compressive modulus similar to that of brain tissue were used for the cell studies. Cytocompatibility and cell type-specific behavior were studied in vitro using human pluripotent stem cell (hPSC)-derived neuronal cells. 


\section{Materials \& Methods}

\subsection{Preparation of $G G$ hydrogels}

To prepare the hydrogels, GG (Gelzan ${ }^{\mathrm{TM}}$, low acyl, $\left.\mathrm{M}_{\mathrm{w}} 1 \mathrm{~kg} / \mathrm{mol}\right)$, SPD (spermidine trihydrochloride), SPM (spermine tetrahydrochloride) and sucrose were acquired from Sigma-Aldrich (Finland) with the highest level of purity available. A $10 \%(\mathrm{w} / \mathrm{w})$ sucrose solution in deionized water was used as a solvent for the hydrogel components to reduce osmotic pressure on the cells [5]. The GG solution was prepared at $5 \mathrm{mg} / \mathrm{ml}$. We tested two different crosslinkers (SPD and SPM); both with three different concentrations, the names and details are shown in table 1.

Table 1. Hydrogel compositions used in this study and calculated details of bioamine per GG in the used concentrations.

\begin{tabular}{|c|c|c|c|c|c|}
\hline $\begin{array}{c}\text { Hydrogel } \\
\text { nomenclature }\end{array}$ & $\begin{array}{c}\text { Bioamine } \\
\text { working } \\
\text { solution }[\mu \mathrm{M}]\end{array}$ & $\begin{array}{c}\text { Bioamine in } \\
\text { hydrogel [w- } \\
\% \text { ] }\end{array}$ & $\begin{array}{c}\text { Bioamine in } \\
\text { hydrogel } \\
{[\mu \mathrm{M}]}\end{array}$ & $\begin{array}{c}\text { Bioamine } \\
\text { Mmoles / } \\
\text { GG [g] }\end{array}$ & $\begin{array}{c}\text { Positive } \\
\text { charge / } \\
\text { GG [g] }\end{array}$ \\
\hline GG $1.10 \%$ SPM & 1005 & 1.108 & 138.7 & 32.17 & 128.7 \\
\hline GG $0.60 \%$ SPM & 502.6 & 0.5569 & 69.43 & 16.08 & 64.33 \\
\hline GG $0.40 \%$ SPM & 395.0 & 0.3984 & 49.52 & 11.49 & 45.95 \\
\hline GG $3.00 \%$ SPD & 3927 & 3.101 & 541.7 & 125.6 & 377.0 \\
\hline GG $1.50 \%$ SPD & 1885 & 1.513 & 260.0 & 60.32 & 180.0 \\
\hline GG $1.25 \%$ SPD & 1551 & 1.248 & 214.0 & 49.64 & 148.9 \\
\hline
\end{tabular}

All solutions were sterile filtered for mechanical and rheological testing with 0.8/0.2 $\mu \mathrm{m}$ Acrodisc $\AA$

(PALL Corporation, Port Washington, NY, USA) or for cell culture with Whatman FP 30/0.2 CA-s 0.2 $\mu \mathrm{m}$ (Whatman plc, Little Chalfont, UK) syringe filters. The GG solution was heated in a water bath to $+60^{\circ} \mathrm{C}$ for reduced viscosity prior to sterile filtration. All solutions can be stored for up to one month at $+4^{\circ} \mathrm{C}$.

When preparing hydrogels, the solutions were first heated in a water bath to $+37^{\circ} \mathrm{C}$. A crosslinker solution of SPM or SPD was mixed with GG at a volume ratio of 4:25 and cast into a suitable mold or directly onto a cell culture plate. When used, laminin $(1 \mathrm{mg} / \mathrm{ml})$ was added to the hydrogel just before gelation in the GG solution at $1 \mathrm{v}-\%, 5 \mathrm{v}-\%$ or $10 \mathrm{v}-\%$. 
This study follows the ASTM F2900-11 Standard Guide for Characterization of Hydrogels Used in Regenerative Medicine [41]. For initial gelation testing and gelation time estimation, a small glass bottle was used as the mold. Gelation time was estimated with the tube tilt test, as described by Tanodekaew at al. [42]. In brief, after mixing the reagents, the bottle was slowly turned upside down at $30 \mathrm{~s}$ time intervals, and the flow of gel was observed. If the solution started to move even slightly once tilting started, it was not tilted further to let the gelation continue. Once the solution did not flow, the gelation was considered complete, and the time was recorded.

\subsection{Mechanical testing}

Compression testing was performed using a BOSE Electroforce Biodynamic 5100 machine equipped with a $225 \mathrm{~N}$ load sensor and Wintest 4.1 software (Bose Corporation, Eden Prairie, Minnesota, USA). Samples were cast into a self-made cylindrical mold with an approximate height of $6.5 \mathrm{~mm}$ and a diameter of $12.2 \mathrm{~mm}$, and stored overnight before compression testing to ensure the complete gelation before each measurement. Each composition was tested in five parallel samples; the exact dimensions of each sample were measured with calipers before testing. To avoid slippage of samples, the compression plates were covered with a piece of wet cellulose paper to increase friction between the hydrogel and the metal plate. The sample was set in between compression plates so that the upper plate touched the sample, but no pre-stress was used. Unconfined compression was performed with a constant $10 \mathrm{~mm} / \mathrm{min}$ strain rate, and samples were compressed until $65 \%$ strain was reached from the original height. The test was performed in wet conditions at room temperature. After compression, the data were analyzed with MS Excel. According to Hooke's law, $\sigma=\mathrm{E}^{*} \varepsilon$, the compressive modulus was calculated from the stress-strain curve as the slope of the elastic region [43]. In addition, the fracture strength and fracture strain were recorded as a sudden drop in the stress-strain curve.

To obtain a good reference in terms of the mechanical properties to design hydrogels for neural TE, compression testing was also performed with brain tissue samples. New Zealand white rabbits, age 10 weeks, male, were sacrificed with deep anesthesia, after which the heads were removed and stored in ice 
for a maximum of 8 hours. The brains were removed from the skulls, and samples containing midbrain, cerebellum or cortex were prepared. The samples were cut with a biopsy punch to the same size and shape as the hydrogel compression samples and stored on ice until compression testing. The test parameters used were the same as those described above. The naïve brain tissues were obtained from animal experiments conducted at Tampere University Medical School, University of Tampere.

\subsection{Rheological testing}

Rheological experiments were carried out with a rotational rheometer (Haake RheoStress RS150) equipped with Rheowizard 4.3 software (ThermoHaake, Germany). Parallel plate geometry with $20 \mathrm{~mm}$ diameter metal plates was used. All the experiments were conducted at room temperature $\left(\sim 25^{\circ} \mathrm{C}\right)$ in the oscillatory mode. In the oscillatory mode the sample is subjected to sinusoidal oscillatory shear strain with amplitude $\gamma_{o}$. In the linear viscoelastic region (LVER) with sufficiently small strain amplitudes the resulting stress will also be sinusoidal of the same frequency with amplitude $\tau_{\mathrm{o}}$ and phase angle $\delta$. The complex moduli $\left(\mathrm{G}^{*}\right)$ represents the rigidity of the sample and in the LVER the following relationship applies:

$$
G^{*}=\frac{\tau_{o}}{\gamma_{o}}=\sqrt{\left(G^{\prime 2}+G^{\prime \prime 2}\right)}
$$

The storage modulus (G') is the in-phase and loss modulus (G'') the out-of-phase components of the response:

$$
\begin{aligned}
G^{\prime} & =\frac{\tau_{o}}{\gamma_{o}} \cos \delta \\
G^{\prime \prime} & =\frac{\tau_{o}}{\gamma_{o}} \sin \delta
\end{aligned}
$$

The G' represents the elastic and G', viscous behavior of the sample. The loss factor tan $\delta$ is the ratio of the viscous to the elastic portion. [44]

The samples for rheological testing were cast in self-made cylindrical molds with height a maximum of $1 \mathrm{~mm}$ and $20 \mathrm{~mm}$ cross-section diameter. Prior to each measurement, the hydrogels were stored overnight to ensure the complete gelation. During measurement the gap between plates was set to $0.8 \mathrm{~mm}$. All 
measurements were done in oscillatory shear deformation mode and both amplitude and frequency sweeps were used for all samples. The strain amplitude range for amplitude sweeps was from 0.01 to 5.00 $\operatorname{rad}(0.1 \mathrm{rad}=1.6 \%$ displacement $)$ with $1 \mathrm{~Hz}$ frequency. Six parallel samples were tested with amplitude sweeps and two parallel samples with frequency sweeps. The frequency sweep was done in range from 0.1 to $3.0 \mathrm{~Hz}$, with constant $0.1 \mathrm{rad}$ strain amplitude which is in the LVER for all samples.

\subsection{Cell culture}

hPSCs, both human embryonic stem cells and human-induced pluripotent stem cells were used in this study [45]. The used hESC-lines were Regea 08/023 [46] and Regea 11/013 [47] and the used hiPSClines were UTA.04511.WT [48], Hel24.3 and A116 [49] (two kind gifts from Prof. Timo Otonkoski, University of Helsinki).

BioMediTech has Pirkanmaa Hospital District's ethical approval to derivate, culture and differentiate hESCs (Skottman, R05116) and permission from the National Authority for Medicolegal Affairs (FIMEA 1426/32/300/05) to conduct human stem cell research. Additionally, approval has been obtained to use hiPSC lines produced by other laboratories for neuronal research (R14023).

\subsubsection{Neuronal differentiation}

The culture and neuronal differentiation of hPSCs were performed as described previously [50]. Briefly, undifferentiated stem cell colonies were mechanically cut into small aggregates and placed in a suspension culture on neural differentiation medium (NDM) containing 1:1 DMEM/F12 (Gibco, Thermo Fisher Scientific, Finland) and Neurobasal medium, 2 mM GlutaMax ${ }^{\mathrm{TM}}, 1$ x B27, 1 x N2 (all from Gibco), $20 \mathrm{ng} / \mathrm{ml}$ basic fibroblast growth factor (bFGF, R\&D Systems, Minneapolis, MN, USA) and 25 $\mathrm{U} / \mathrm{ml}$ penicillin/streptomycin (Cambrex, Belgium). During suspension culture, the cell aggregates formed round, floating neurospheres. Neurospheres were kept small via mechanical cutting once per week, and $1 / 3$ of the medium was changed three times per week. Cells were kept for 8-17 weeks in the differentiation phase prior to the hydrogel experiments. Cells were under constant monitoring for the 
quality of differentiation. Only experiments in which cells formed good neuronal cultures in 2D control were included to the analysis (representative images of good quality 2D cultures in supplemental figure 1).

\subsubsection{Hydrogel cell culture experiments}

For the biological evaluation of the hydrogels, three approaches were taken to study the cell/biomaterial interactions as shown in figure 1. In every case, control cells were plated on laminin-coated cell culture wells (positive control) and on non-coated cell culture wells (negative control). Cell behavior on the studied materials was always compared to that of the controls. Depending on the well type used, either plastic (Nalge Nunc International, Rochester, NY, USA) or glass bottom (MatTek Corporation, Ashland, MA, USA), the wells were coated either with laminin (10 $\mu \mathrm{g} / \mathrm{ml}$ mouse laminin) or poly-L-lysine and laminin (10 $\mu \mathrm{g} / \mathrm{ml}$ poly-L-lysine followed by $10 \mu \mathrm{g} / \mathrm{ml}$ mouse laminin), respectively. 
Cells beneath the gel

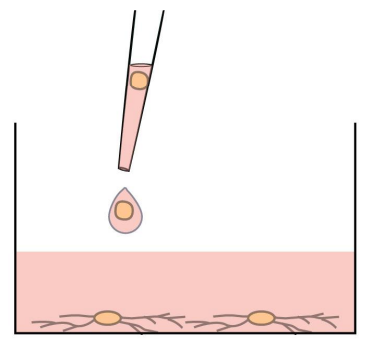

Step 1. Plate cells on coated well, culture for one week

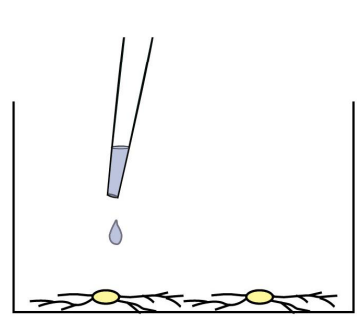

Step 2. Drain wells and add crosslinker

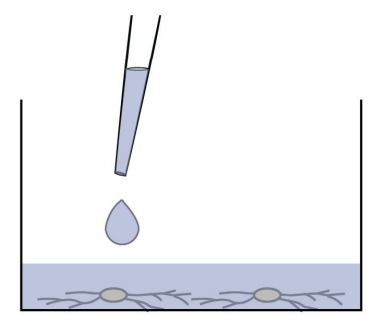

Step 3. Add gellan gum solution and wait for gelation

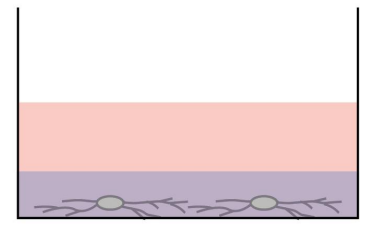

Step 4. Add medium

Culturing cells on top of the gel

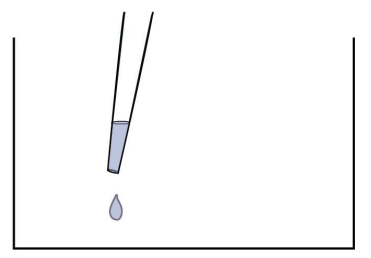

Step 1. Add crosslinker

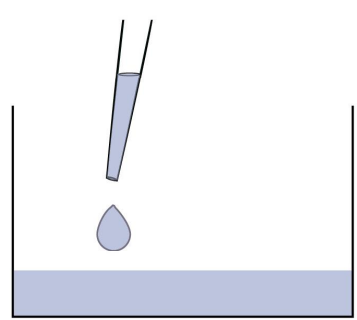

Step 2. Add gellan gum solution, mix and wait for gelation

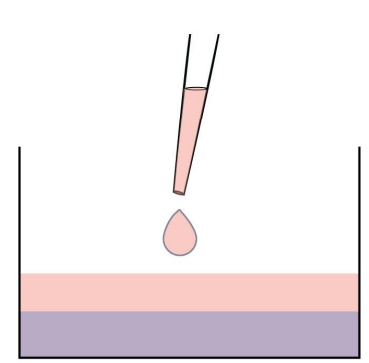

Step 3. Add medium

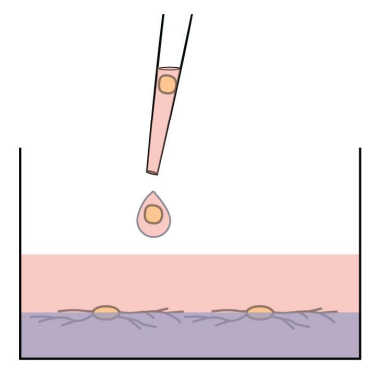

Step 4. Plate cells on top of the gel

Encapsulating cells inside the gel

(Optional step 1 for gels with slow gelation)

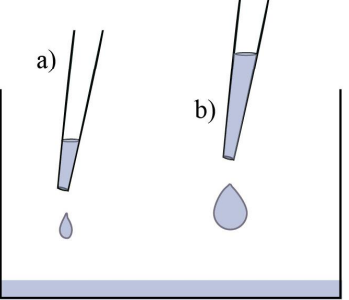

(Optional) Step 1. a) add crosslinker, b) gellan gum solution, mix and wait for gelation

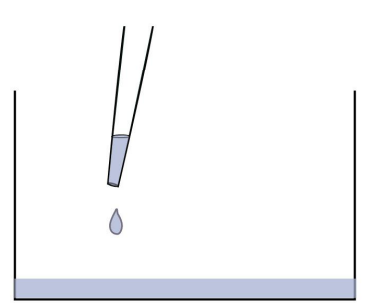

Step 2. Add crosslinker

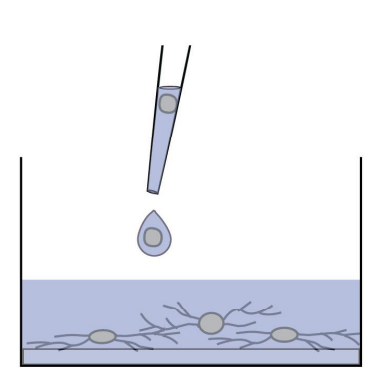

Step 3. Add gellan gum solution with the cells, mix and wait for gelation

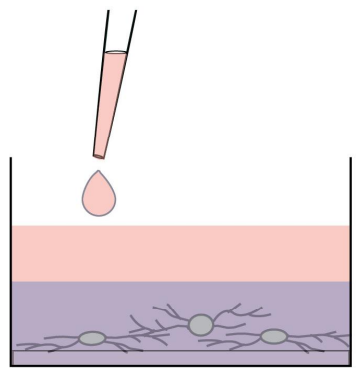

Step 4. Add medium

Figure 1. Schematic presentation of plating cells with the hydrogels. All components were kept at $37^{\circ} \mathrm{C}$ to ensure homogeneous and complete gelation.

Gelation was performed as described in figure 1. A drop of crosslinking agent was added on top of the cell culture, followed by the gentle addition of GG solution, in case of cultures beneath the gel. To avoid disturbing the cells, no additional mixing was performed. For cell encapsulation, the cells were suspended in GG solution with a minimal amount of medium prior to crosslinking. After complete gelation, medium was gently added on top of the gel. In 3D cell encapsulation studies for gels with slow gelation (all except 
GG 3.00\%SPD), a thin bottom layer of gel was cast beforehand to prevent cell aggregates from sedimenting to the well bottom during gelation.

\subsubsection{Cell plating}

Cells were plated either as mechanically cut small cell aggregates or as enzymatically dissociated single cell suspensions prepared using $1 \mathrm{X}$ TrypLE Select (Gibco). For the 2D experiments (controls, cells embedded or on top), the plating density was 60,000 cells $/ \mathrm{cm}^{2}$ or $7-20$ small aggregates $/ \mathrm{cm}^{2}(3000-7000$ cells/aggregate). The cell density for the 3D experiments (cells encapsulated) was $\sim 3.5 \times 10^{6}$ cells $/ \mathrm{ml}$ of gel, or a corresponding amount of small mechanically cut cell aggregates.

The cells were cultured with the gel for 2 weeks. NDM without bFGF was used during the first week of the experiments. After one week of culture, NDM containing $5 \mathrm{ng} / \mathrm{ml} \mathrm{bFGF}$ and $4 \mathrm{ng} / \mathrm{ml}$ brain-derived neurotrophic factor (BDNF, Prospec Bio, Germany) was used. Half of the medium was changed three times per week using caution to avoid disrupting the gels.

Cells were imaged using a Zeiss AxioVert.A1 microscope and AxioCam ERc 5s camera system or with a Nikon Eclipse TE 2000-S and Nikon Digital Sight DS-Fi1 camera system during the culturing period.

\subsection{Liveldead staining}

For viability analysis, the cultures were stained using a LIVE/DEAD ${ }^{\circledR}$ viability/cytotoxicity assay (Molecular probes, Thermo Fisher Scientific). In brief, there are two fluorescent dyes in the kit. Calcein$\mathrm{AM}\left(0.1 \mu \mathrm{M}, \lambda^{\text {emission }}=488 \mathrm{~nm}\right)$ stains intact cells, and ethidium homodimer-1 $\left(0.4 \mu \mathrm{M}, \lambda^{\text {excitation }}=568\right.$ $\mathrm{nm}$ ) stains dead cells. After $1 \mathrm{~h}$ of incubation at $+37^{\circ} \mathrm{C}$, the cells were imaged with an Olympus IX51 inverted microscope and an Olympus DP30BW digital camera (Olympus, Finland). The numbers of parallel samples varied between 2 and 4 .

\subsection{Immunostaining}

We optimized the parameters for immunostaining cells within macroscopic (60-300 $\mu \mathrm{l})$ hydrogel blocks. In brief, cultures were fixed with $4 \%$ paraformaldehyde preheated to $+37^{\circ} \mathrm{C}$ for $30 \mathrm{~min}$. After a brief wash 
in phosphate buffered saline (PBS), non-specific staining was blocked with $10 \%$ normal donkey serum (NDS), $0.1 \%$ Triton $\mathrm{X}-100$, and $1 \%$ bovine serum albumin (BSA) in PBS for $1 \mathrm{~h}$ at room temperature, followed by another wash in $1 \%$ NDS, $0.1 \%$ Triton X-100, and 1\% BSA in PBS. Then, the cells were incubated with a combination of primary antibodies at $+4^{\circ} \mathrm{C}$ for at least 2 days. These antibodies included rabbit anti-microtubule associated protein 2 (MAP-2, 1:400, AB5622, Merck Millipore, Darmstadt, Germany) and rabbit anti- $\beta$-tubulin isotype III ( $\beta$-tub, 1:1000, A01627, GenScript, Piscataway, NJ, USA) in $1 \%$ NDS, $0.1 \%$ Triton X-100, and 1\% BSA in PBS. The samples were washed three times in $1 \%$ BSA in PBS (first briefly followed by $2 \times 1$ hour washes) and then incubated overnight at $+4^{\circ} \mathrm{C}$ with Alexa Fluor 488 conjugated to donkey anti-rabbit antibody (1:400, Life Technologies, A21206) and tetramethylrhodamine isothiocyanate conjugated to phalloidin (TRITC-phalloidin, $0.625 \mu \mathrm{g} / \mathrm{ml}$, Sigma Aldrich, P1951) in 1\% BSA in PBS. The samples were washed three times (first briefly followed by 2 x 1 hour washes) in PBS and then mounted with VECTASHIELD containing 4',6-diamidino-2-phenylindole (DAPI, Vector Laboratories, England). They were then imaged with an Olympus IX51 inverted microscope and an Olympus DP30BW digital camera. Confocal scanning of the samples was performed with a Zeiss LSM 780 mounted into inverted Cell Observer microscope (Carl Zeiss, Jena, Germany) using $10 \times$ (NA. 0.45 ) or $20 \times$ (NA. 0.80 ) air objectives. The samples were scanned through \#1.5 glass bottom well plates (MatTek Corporation, Ashland, MA, USA) or through high performance \#1.5 coverslips (Carl Zeiss). The confocal data were visualized with the ZEN Black 2012 software (Carl Zeiss) and Image (Version 1.39, U. S. National Institutes of Health, Bethesda, Maryland, USA) [51; 52].

\subsection{Neurite migration}

Neurite migration measurements were performed with the ImageJ measure tool. Migration was measured using a straight line from the cell aggregate surface to the visible end of a neuronal process. Each analyzed cell aggregate was measured from 4 longest separately distinguishable neurites. Values of less than $10 \mu \mathrm{m}$ were considered as representing no migration. The analysis was conducted with at least 2 
individual experiments with at least 2 replicative wells. For each studied group, 7 to 16 images were analyzed.

\subsection{Statistical analysis}

Due to the non-Gaussian distribution of the data, the nonparametric Kruskal Wallis test and MannWhitney U-test were used. A p value of less than 0.05 was considered significant. If more than two groups were compared, the resulting $\mathrm{p}$ values were multiplied by the number of comparisons performed (Bonferroni correction). 


\section{Results}

\subsection{Gel forming and gelation time}

GG hydrogels were formed with bioamine weight percentage varying from $0.40 \%$ to $1.10 \%$ for SPM and from $1.25 \%$ to $3.00 \%$ for SPD. With these concentrations, the hydrogels were transparent and strong enough to hold their own weight and be handled with tweezers. Higher crosslinker concentrations caused partial gelation of the solutions before they could be mixed uniformly, resulting in high anisotropy with non-transparent (cloudy) areas. Lower crosslinker concentrations formed weak gels that could not support their own weight and were not suitable for 3D cell culture, as the encapsulated cells would sediment to the bottom of gel. The $10 \mathrm{v}-\%$ or lower laminin additions did not affect gelation.

The gelation times approximated with tube tilt test are listed in table 2. As seen, the fastest gelation times were just a few seconds, which could cause difficulties in mixing the reagents evenly and cause anisotropic gels. Gelation times over 10 minutes were so slow that during plating the cells could sediment to the bottom of the gel before the gelation is completed. From a practical point of view, a gelation time of 1-5 minutes is optimal, as it is long enough to mix the components uniformly but short enough to keep the cells suspended in the 3D gel and prevent them from sedimenting to the bottom.

Table 2. The gelation times determined by the tube tilt test

\begin{tabular}{ccccccc}
\hline Gel composition & $1.10 \% \mathrm{SPM}$ & $0.60 \% \mathrm{SPM}$ & $0.40 \% \mathrm{SPM}$ & $3.00 \% \mathrm{SPD}$ & $1.50 \% \mathrm{SPD}$ & $1.25 \% \mathrm{SPD}$ \\
\hline Gelation time & $1 \mathrm{~min}$ & $5 \mathrm{~min}$ & $10 \mathrm{~min}$ & $5 \mathrm{sec}$ & $5 \mathrm{~min}$ & $10 \mathrm{~min}$ \\
\hline
\end{tabular}

\subsection{Compression testing}

The main variable influencing the mechanical properties of hydrogels in this study was the crosslinker concentration. The upper and lower limits of crosslinking were tested along with one concentration between the extremes. The compression testing data were analyzed as stress-strain curves (figure 2), from which the compressive modulus (figure 3 ) was calculated as the slope of the elastic region. In all GG samples, a distinct fracture point was observed during the test. In contrast, the rabbit brain samples did not have a clear fracture point in the measured displacement but rather a more rubber-like elastic behavior 
with strong strain stiffening in the end. The GG $0.40 \%$ SPM was almost too soft for the load cell, with the force varying during measurement between only $0.01-0.12 \mathrm{~N}$.

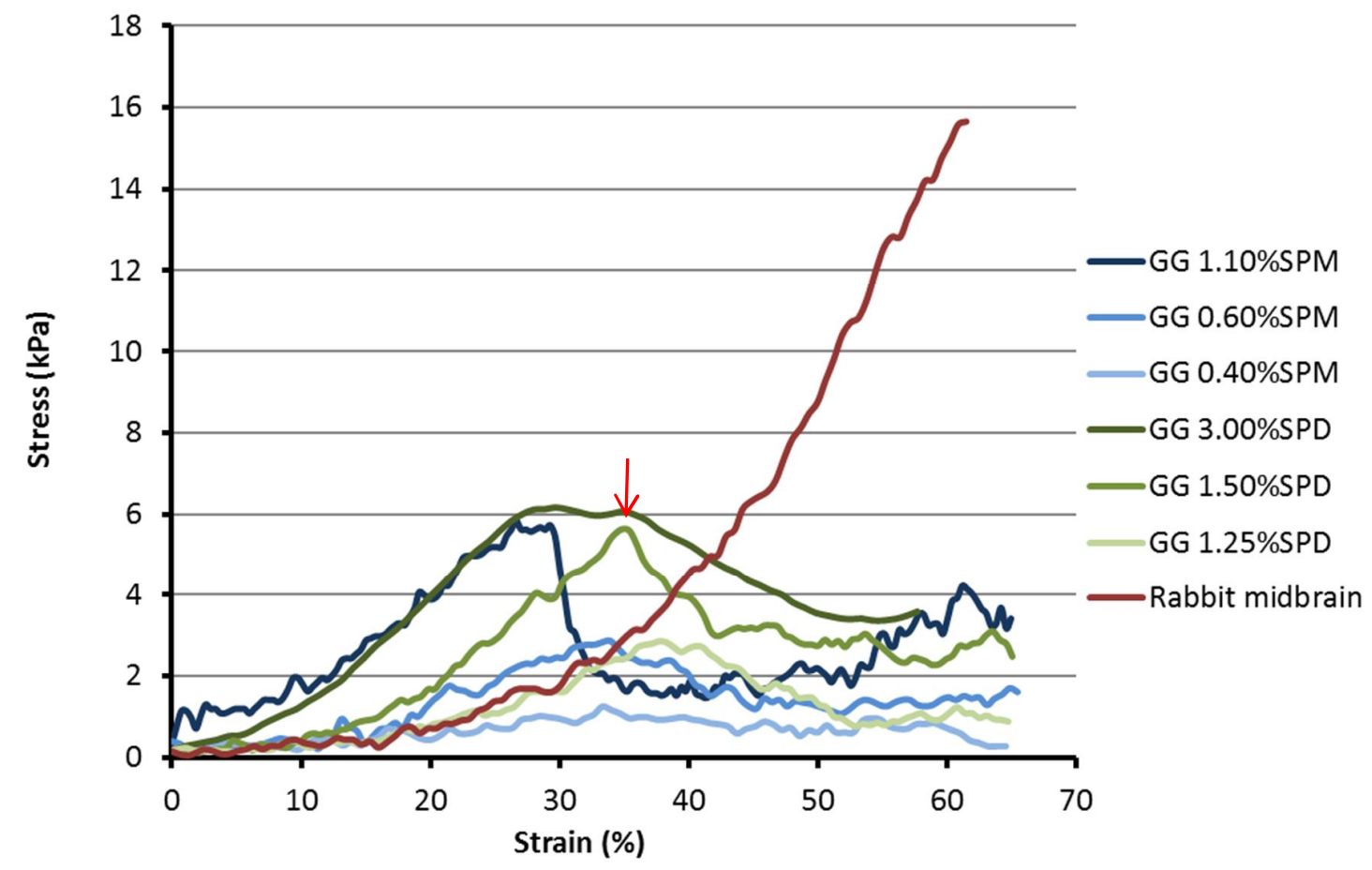

Figure 2. Representative stress-strain curves of GG and brain tissue compression testing. The linear elastic region was determined individually for each sample and ranged from approximately $0.1-0.35$ $\mathrm{mm} / \mathrm{mm}$ strain. As an example, the fracture point of GG $1.50 \%$ SPD is marked with a red arrow.

Based on figure 2, it is clear that brain tissue is more ductile than any of the hydrogel samples as it can endure more plastic deformation without fracture than the GG samples. However, the elastic regions at strain of approximately $0.1-0.35 \mathrm{~mm} / \mathrm{mm}$ of GG $0.60 \% \mathrm{SPM}$ and GG $1.25 \% \mathrm{SPM}$ are very similar to those of the brain stress-strain curve, resulting in both cases in a compressive modulus of approximately 10 $\mathrm{kPa}$. The comparison of calculated compressive moduli is shown in figure 3. The strongest compositions, GG 1.10\%SPM and GG 3.00\%SPD, both have a 23 kPa modulus, whereas the weakest composition, GG $0.40 \% \mathrm{SPM}$, has only a $3.9 \mathrm{kPa}$ modulus. A significant, linear decrease in the compressive modulus is seen with both crosslinkers when lowering the concentration. The addition of laminin did not affect the 
compressive modulus (data not shown). The part of the stress-strain curve after the fracture point is negligible. The different parts of the rabbit brain, midbrain, cerebellum and cortex, all behaved very similarly throughout the compression testing, with compressive moduli in the 7-10 $\mathrm{kPa}$ range.

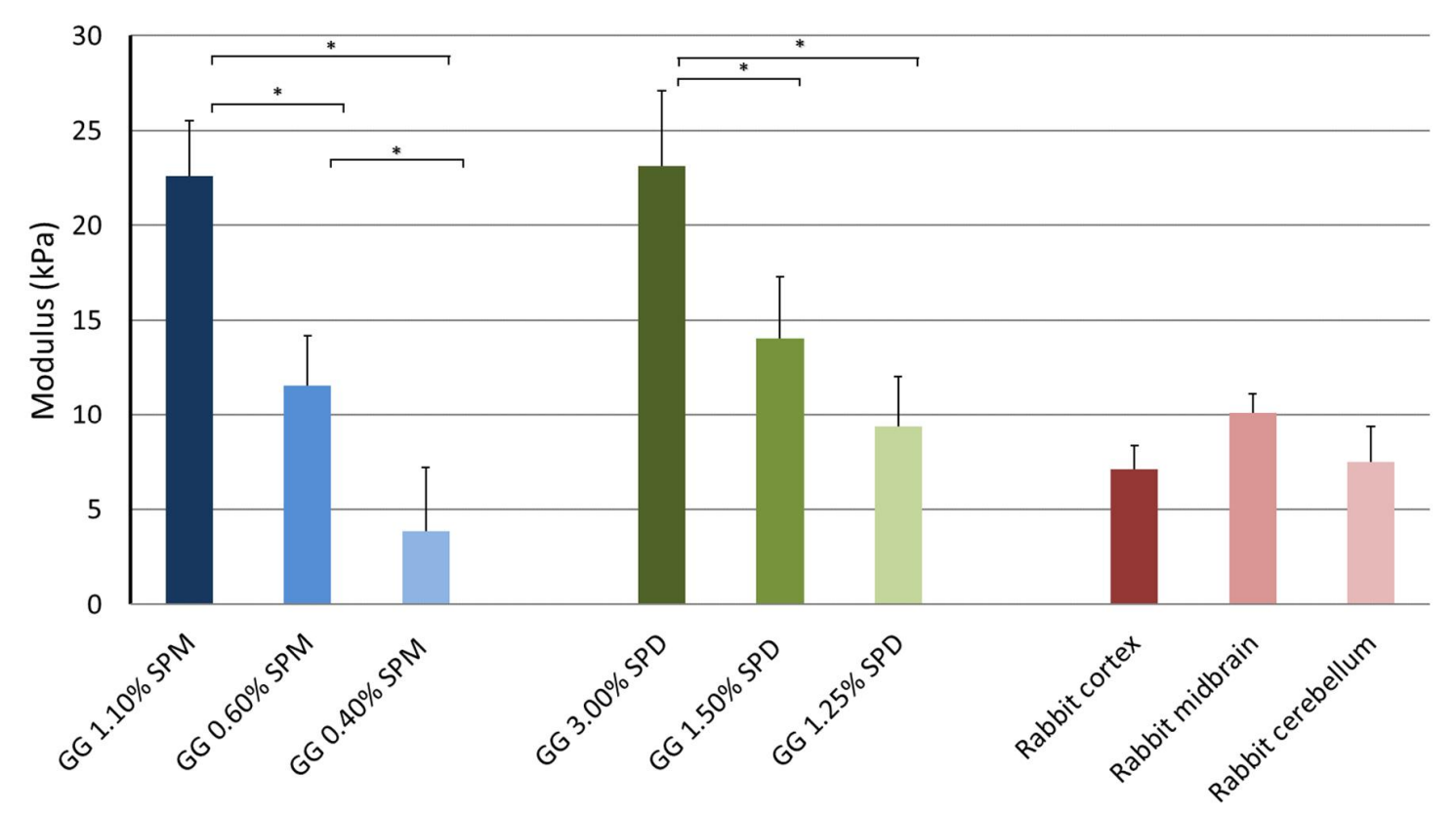

Figure 3. Average compressive moduli of GG bioamine hydrogels and brain tissue samples with error bars showing the standard deviation, $\mathrm{n}=5, *=$ significant at $\mathrm{p} \leq 0.05$.

The compressive moduli of the hydrogel can be tuned by varying the bioamine concentration, and similar mechanical properties can be achieved with either crosslinker. The compressive moduli of cortex samples were in the same range as the hydrogel moduli with the lowest crosslinker concentrations: GG $0.40 \%$ SPM vs. GG $1.25 \%$ SPD ( $p>0.05$ ). The standard deviation was approximately $2.5-3.5 \mathrm{kPa}$ in all measurements. This result indicates that the calculated moduli less than $5 \mathrm{kPa}$ are not very accurate, being on the lower limit of the compression testing machine load sensor capability. The dependence of the compressive modulus on the crosslinker concentration is linear and within the limits of the standard deviation, as shown in figure 4. SPM has a tetravalent charge, so the rise of the modulus with increasing crosslinker concentration is steeper than that of trivalent SPD. 


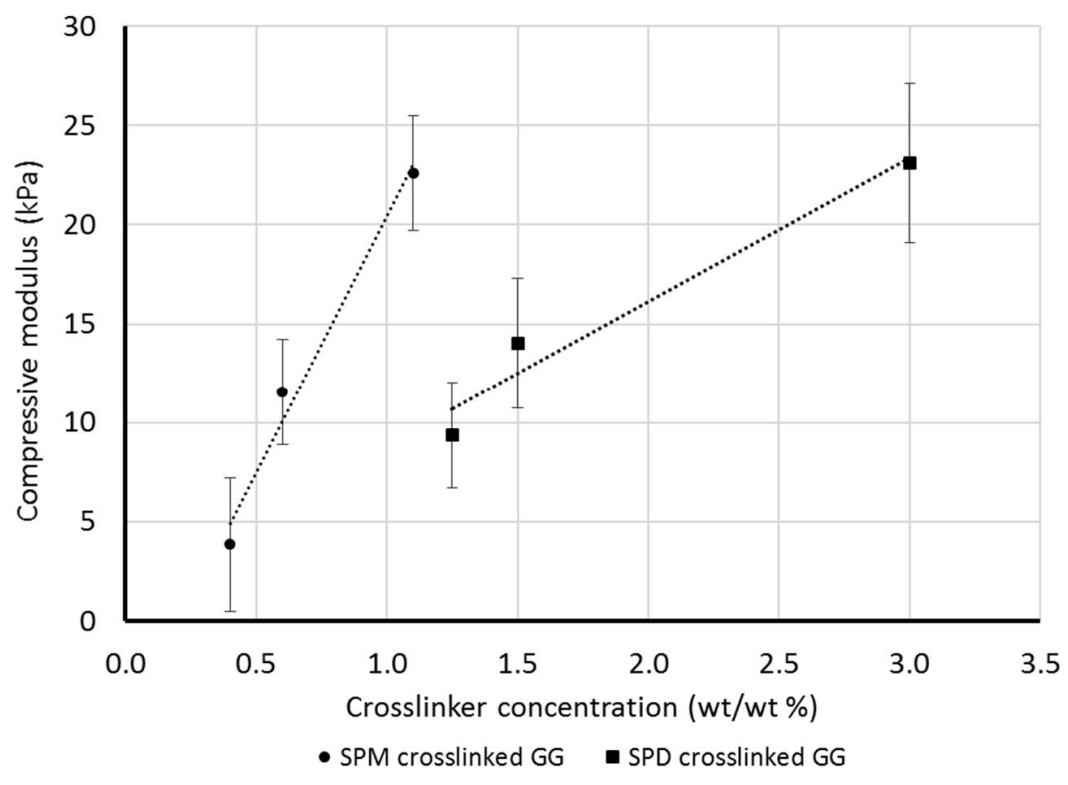

Figure 4. The dependence of the hydrogel compressive modulus on the crosslinker concentration is linear and within the limits of standard deviation as shown by error bars, $n=5$. The trend line fit to the average modulus values was determined using MS Excel.

The fracture strength (figure 5) is the ultimate amount of stress a sample can endure, and this value can be critical for load-bearing TE applications even though a cell's mechanotransduction is likely not affected by it. A significant decrease in fracture strength is seen when the crosslinker concentration is lowered. The fracture strain (figure 5) is an indicator of the brittleness of the sample, and the more crosslinker, the more brittle the hydrogel. The brain tissue samples did not have a visible fracture point when compressed to $65 \%$ of the original height, but they had a strong strain hardening effect, as shown in figure 2. However, the strain hardening occurred in the plastic deformation region because the deformation was not recoverable (data not shown). 


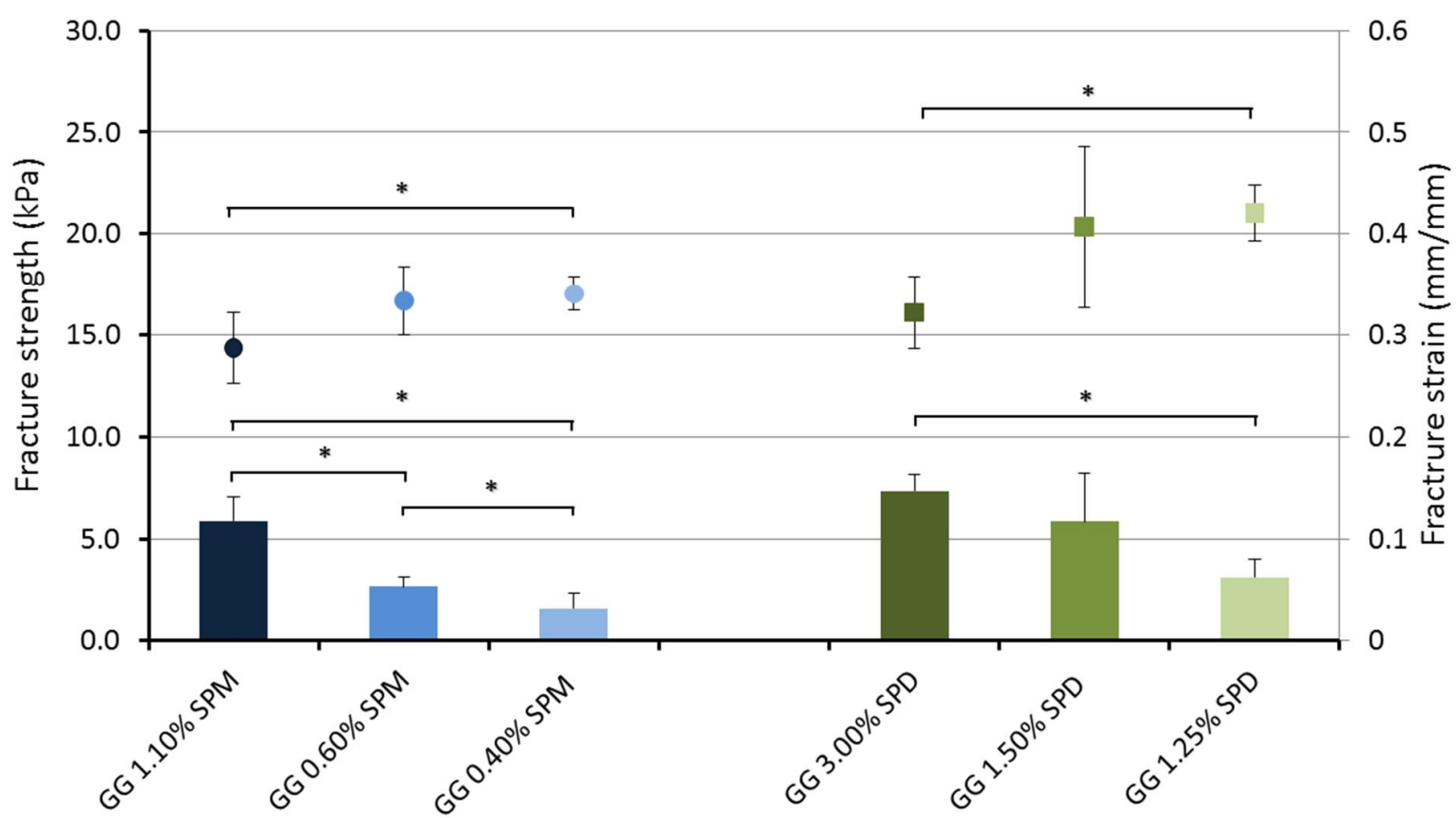

Figure 5. The measured fracture strength is shown on the primary y-axis as bars, and fracture strain is shown on the secondary y-axis as dots. For each hydrogel composition $(n=5)$, error bars represent standard deviation, $*=$ significant $\mathrm{p} \leq 0.05$. Brain tissue samples did not have a clear fracture point, so they are excluded from the graph.

\subsection{Rheological testing}

The low amplitude strain of the rheological spectrum measured with oscillatory shear amplitude sweep showed a discernible LVER for GG SPM hydrogels, which is used to calculate the complex modulus (figure 6 (d)). At higher strain, a decline due to plastic deformation leads to fracture of the sample at the crossover point of the storage and loss modulus as shown in the figure 6 spectra. All the GG SPM hydrogels have a typical gel-like behavior in the LVER with the storage modulus higher than the loss modulus (G' > G'), which means that elastic behavior dominates over viscous behavior and that the material is more solid than liquid. As shown in figure 6 (a-c) by decrease in the phase angle and $\tan \delta$ value in LVER, when the crosslinker concentration increases, the solid-like behavior increases. And 
similar to the compressive modulus, the complex modulus decreased upon lowering the crosslinker concentration.
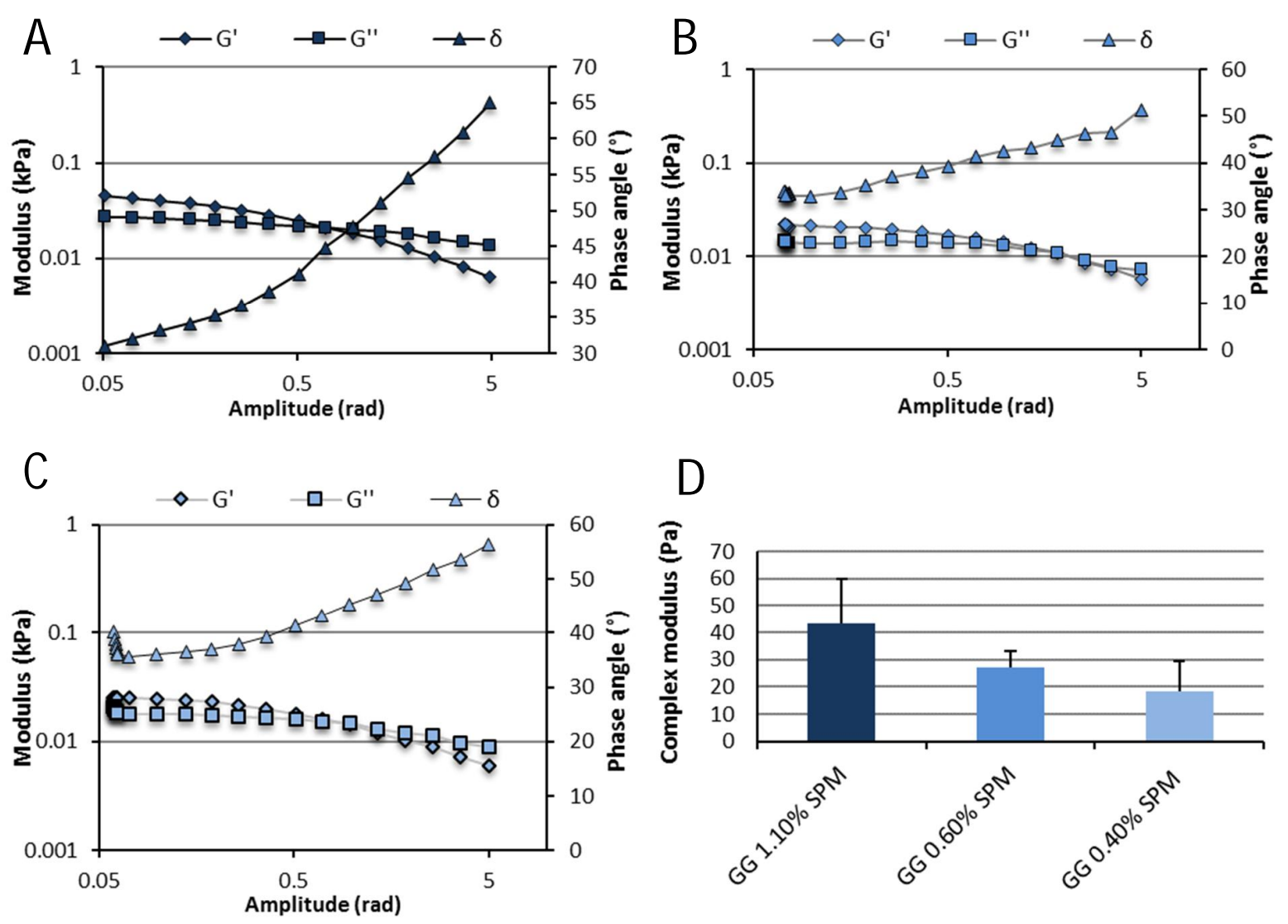

Figure 6. Rotational rheological spectra of (a) GG 1.1\%SPM, (b) GG 0.60\%SPM and (c) GG 0.40\%SPM in amplitude sweep and (d) complex moduli of all GG SPM hydrogels. The LVER exceeds to $0.1 \mathrm{rad}$ amplitude and the gel breaking takes place around $1.0 \mathrm{rad}$.

Only SPM crosslinked hydrogels displayed distinctive gel-like behavior related to a stable 3D network structure, which was confirmed by a straight line in the frequency sweep (data not shown). The SPD crosslinked gels did not have a discernible LVER, likely due to anisotropy or being too solid for rheology, and thus were not possible to measure with this method. The very quick gelation of SPD crosslinked gels can cause nucleation of crosslinking spots. This nucleation leads to anisotropy of gel network structure and density variations, which are not seen in compression testing. 


\subsection{Neuronal cell cultures beneath the hydrogels}

Neuronal cells were cultured for one week on the plastic dish before casting gel over the cells. The gelation process on top of cultures did not cause any acute cytotoxic effects. During prolonged culture (up to two weeks) beneath the hydrogel, the neuronal cells remained viable, and neuronal maturation continued similarly as in the positive control cultures without the GG. Culturing beneath the hydrogel did not cause any morphological changes compared to control 2D cultures (figure 7 (a)). In the cell viability analysis, all studied cases had similar degrees of cell viability by visual inspection (figure 7 (b)). Neuronal cultures beneath hydrogel also had similar neuronal protein expression according to immunocytochemical analysis as control cultures without hydrogel (figure 7 (c)). Figure 7 shows the representative images of cultures beneath hydrogel with highest the crosslinker concentration and a 2D positive control. The results were similar at all studied crosslinker concentrations (SPD 3.00\%, 1.50\%, and 1.25\% or SPM $1.10 \%, 0.60 \%$, and $0.40 \%$, figure 7, data not shown). Thus, SPD and SPM crosslinkers enable the formation of GG hydrogels that are compatible with culturing human neuronal cells. The hydrogel layers (height 2.2-2.8 mm) on top of the neuronal cultures enabled prolonged culturing, implying that the porosity of the formed hydrogels was high enough for nutrient and metabolite exchange. 

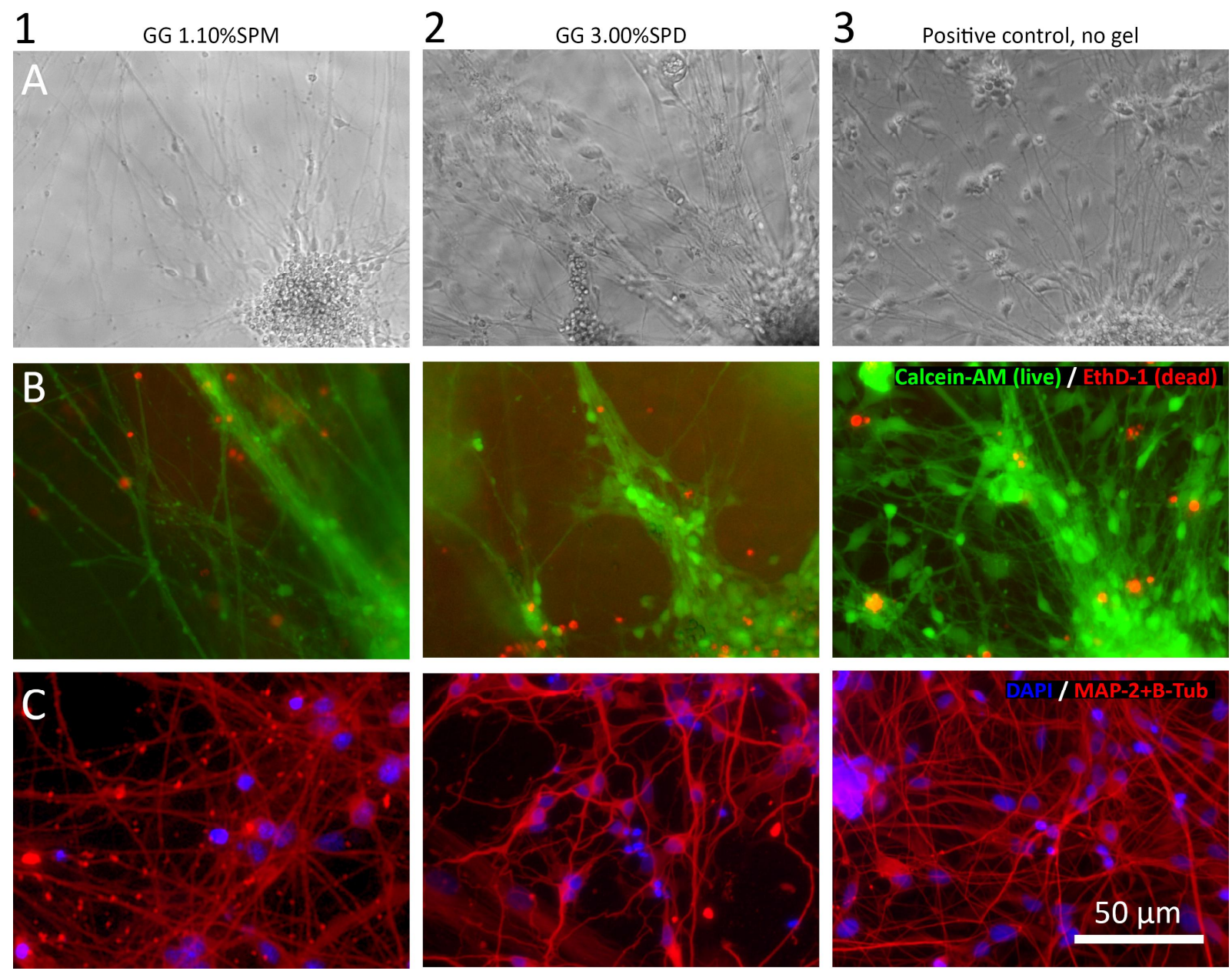

Figure 7. Neuronal cultures beneath the gels. Cells were pre-cultured on a laminin coating for one week, thereafter the gel was cast over the cells and then cultured for 2 additional weeks before analysis. The representative images are shown for the highest crosslinker concentrations, that is, SPM $1.10 \%$ (column 1) and SPD 3.00\% (column 2) and for the positive 2D control (column 3). Phase contrast images (a), cell viability analysis (b) and immunocytochemistry (c) are shown. Row B: Green = Calcein-AM, live cells, red $=$ EthD-1, dead cells. Row C: Blue = DAPI, Red = MAP-2+B-tub. Scale bar for all images $50 \mu \mathrm{m}$.

\subsection{Neuronal cell behavior on top of the hydrogels}

Neuronal cells remained viable during prolonged culturing ( 2 weeks) when plated on top of pre-cast hydrogels (success rate 100\%, figure 8). For cell type-specific behavior, neurite migration was studied in more detail. Although neuronal cells remained alive on top of all the studied hydrogels, their spreading 
and migration along the hydrogel surfaces varied within and between groups. Figure 8 shows a summary of the results. Without any functionalization with laminin, the GG $1.10 \%$ SPM and GG $0.60 \%$ SPM were the best compositions for supporting neuronal cell spreading (figure 8 (a)). When a low concentration of laminin ( $1 \mathrm{v}-\%)$ was added, the performance of the GG 3.00\%SPD hydrogel was superior to any other tested gel composition. (figure 8 (a)). As GG 3.00\%SPD with laminin functionalization gave the best results in neuronal cell spreading and migration, functionalization with higher laminin concentrations was further studied.

\begin{tabular}{|c|c|c|c|c|c|c|}
\hline Crosslinker & $\begin{array}{c}\text { Crosslinker } \\
\text { concentration }[\mathrm{w}-\%]\end{array}$ & $\begin{array}{l}\text { Compression } \\
\text { modulus }[\mathrm{kPa}]\end{array}$ & $\begin{array}{c}\text { Functionalization } \\
\text { laminin }[\mathrm{v}-\%]\end{array}$ & $\begin{array}{c}\text { Number of } \\
\text { experiments }\end{array}$ & $\begin{array}{l}\% \text { of succesful } \\
\text { experiments }\end{array}$ & $\begin{array}{c}\% \text { of experiments } \\
\text { with migration }\end{array}$ \\
\hline \multirow{3}{*}{ SPM } & $1.10 \%$ & 22.6 & - & 7 & $100 \%$ & $57 \%$ \\
\hline & $0.60 \%$ & 11.5 & - & 3 & $100 \%$ & $67 \%$ \\
\hline & $0.40 \%$ & 2.7 & - & 3 & $100 \%$ & $33 \%$ \\
\hline \multirow{3}{*}{ SPD } & $3.00 \%$ & 23.1 & - & 9 & $100 \%$ & $44 \%$ \\
\hline & $1.50 \%$ & 11.3 & - & 2 & $100 \%$ & $50 \%$ \\
\hline & $1.25 \%$ & 9.4 & - & 2 & $100 \%$ & $50 \%$ \\
\hline
\end{tabular}

${ }^{1}$ Number of replicative wells was at least 2 in all experiments
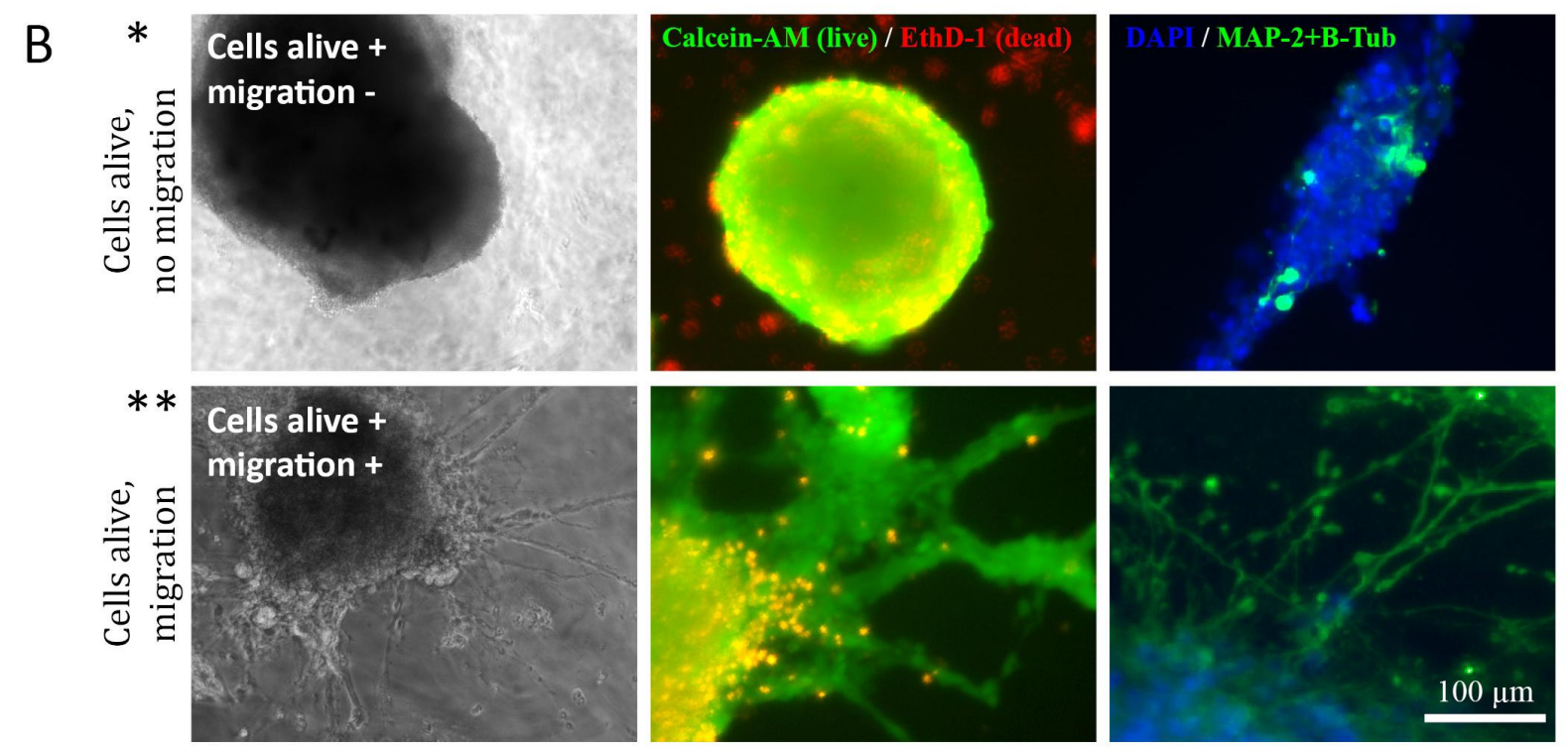

Figure 8. Cell viability and spreading were analyzed on top of GG hydrogel surfaces crosslinked using either SPD (1.25-3.00\%) or SPM (0.40-1.10\%). With 3.00\%SPD and 1.10\%SPM, the effects of functionalization with laminin were also tested. All experiments were considered successful, as the cells 
were alive in all experiments even though neurite outgrowth was not seen in all cases (a). The best neurite migration was seen in $3.00 \%$ SPD crosslinked gel with $1 \%$ laminin $\left(a^{* *}, b^{* *}\right)$. Representative images of cultures on top of $3.00 \%$ SPD crosslinked gel with $1 \%$ laminin (b). In some experiments cells were alive, but no migration was seen $\left(a^{*}, b^{*}\right)$, while in other experiments the cells did migrate along the gel surface $\left(a^{* *}, b^{* *}\right)$. (b) second column: Green $=$ Calcein-AM, live cells, red = EthD-1, dead cells, $($ b) third column, Blue: DAPI, Green: MAP-2+B-tub. Scale bar for all images $100 \mu \mathrm{m}$.

\subsection{Effect of laminin concentration on SPD crosslinked gels}

The addition of laminin ( $5 \mathrm{v}-\%$ and $10 \mathrm{v}-\%)$ significantly increased neurite migration on top of gel surfaces during prolonged culturing time ( 2 weeks). Laminin addition increased both the length of the neurites (figure 9 (a)) and the number of neurites (figure 9 (b)). The most obvious increase in neurite migration was seen on top of GG 3.00\%SPD, but a similar trend was also observed with $1.5 \%$ SPD and $1.25 \%$ SPD gels (data not shown).
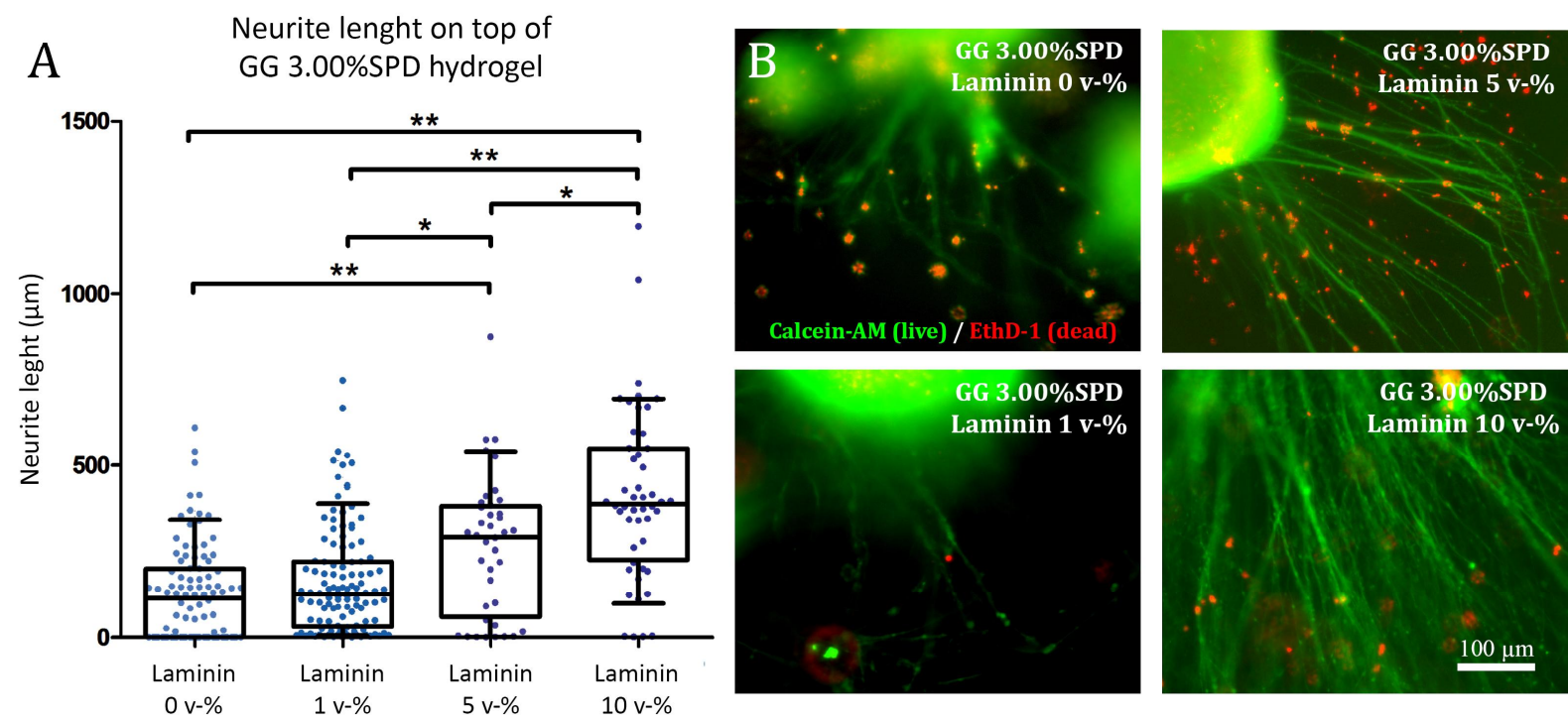

Figure 9. Neurite migration in human derived neuronal cells cultured for 2 weeks on top of GG hydrogels.

Laminin enhances migration in a concentration-dependent manner. Neurite length distribution in SPD crosslinked gels with different laminin concentrations (a). The box shows $50 \%$ of samples and the 
median, and the whiskers show $90 \%$ of samples. The value of each measured neurite is shown as a dot in the background. Representative images of neurite migration in each laminin concentration (b). By visual inspection, the laminin concentration increased the amount of neurite outgrowth. Green $=$ live cells, red $=$ dead cells. Scale bar $100 \mu \mathrm{m}$ for all images. $*=p \leq 0.05, * *=p \leq 0.0001$.

\subsection{Neuronal cells encapsulated inside the gel}

Neuronal cells were cultured as encapsulated in GG hydrogels for two weeks. Cells remained viable inside all the studied GG bioamine compositions (data not shown). Due to promising neurite migration results obtained from cultures on top of the laminin functionalized GG 3.00\%SPD hydrogel, this composition was studied further. Neurite migration was observed in cultures inside the GG 3.00\%SPD hydrogel both with and without functionalization with laminin (0-10 v-\%). The amount of neurites migrating from the cell aggregates varied from zero to dense outgrowth from aggregate to aggregate (example images of dense outgrowth are presented in figure 10). Neither neurite amount nor neurite length were affected by laminin concentration of hydrogel. Variation observed was also cell line or cell source independent (supplemental figure 1). The neuronal cells cultured encapsulated inside the GG hydrogel formed 3D neuronal network expressing typical neuronal markers (MAP-2 and $\beta$-tubulin III) $_{\text {co- }}$ labelled with phalloidin, (supplemental video 1). 


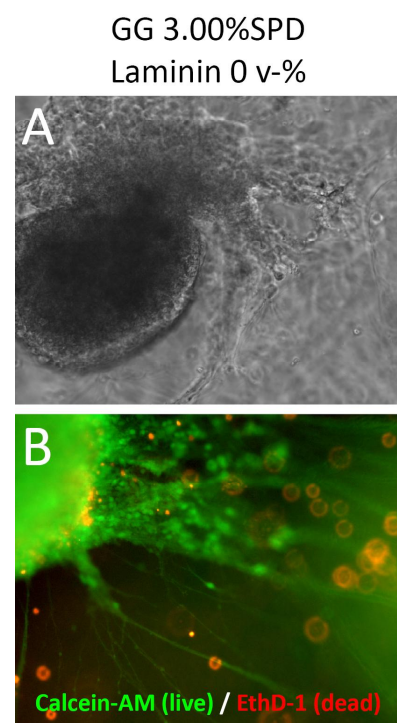

GG 3.00\%SPD

Laminin $1 \mathrm{v}-\%$
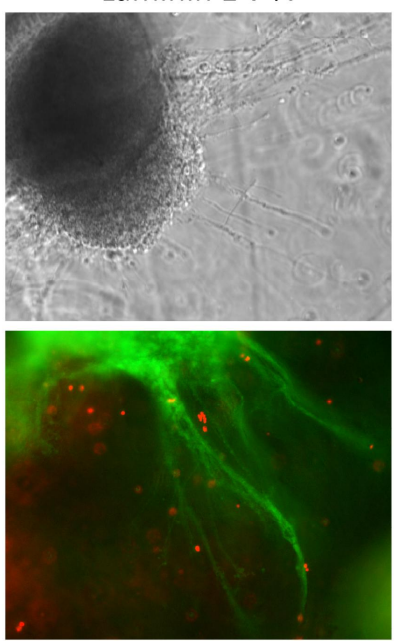

GG $3.00 \%$ SPD

Laminin $5 \mathrm{v}-\%$
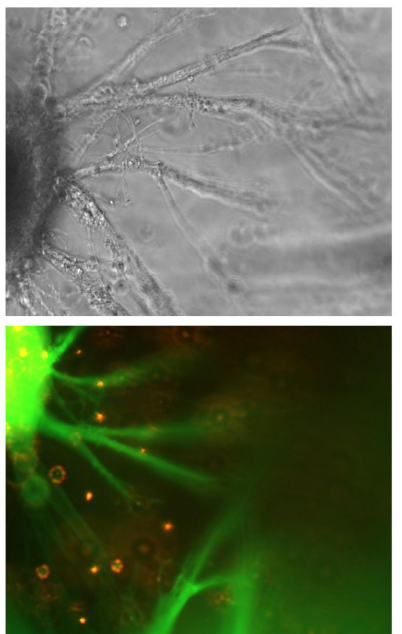

GG 3.00\%SPD Laminin $10 \mathrm{v}$-\%
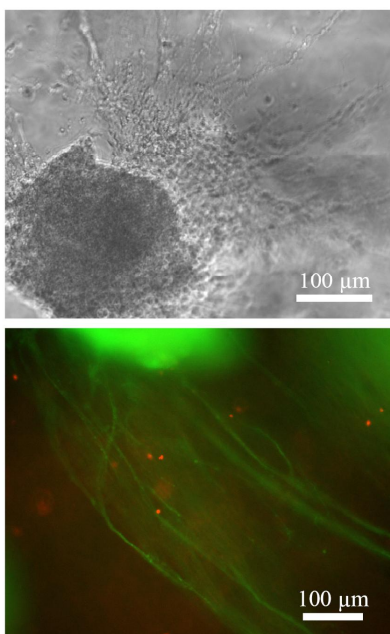

Figure 10. Neuronal cell aggregates cultured for 2 weeks inside the GG 3.00\%SPD gel. Phase-contrast images (a) and Live/Dead images of cultures (b). Green = live cells, red = dead cells. Scale bar $100 \mu \mathrm{m}$ for all images. 


\section{Discussion}

\subsection{Bioamine crosslinked $G G$}

GG has been approved by the FDA and EMA for food, cosmetic and pharmaceutical applications as a gelling or emulsion agent [15]. Taking advantage of the wide usage, GG has been applied for TE with promising results $[15 ; 27 ; 28]$. The common method of physical/ionotropic crosslinking of polysaccharides with metallic cations in order to form hydrogels has some inherent problems: Controlling the crosslinking process and tuning of properties is challenging [30]. With this fact in mind, we tested the ability of bioamines for physical crosslinking of GG. The study of alternative ionotropic crosslinking methods using bioamines for anionic polymers in TE is relatively new [34; 35] and those studies focused on the development of multicomponent hydrogels for drug delivery applications [35]. On the other hand, we have addressed the GG-based bioamine crosslinked hydrogels specifically as a 3D cell culture scaffold for neural TE applications. Other forms of GG have already been studied in spinal cord injury rodent models [23-27], but not with these alternative crosslinking methods. The small cationic bioamine molecules worked efficiently and in a broad range of concentrations, producing stable hydrogels with tuneable mechanical properties.

The definition of a true gel is a material that responds to high stress by fracturing and is self-supporting, whereas a weak gel is a structured fluid that flows under stress [13]. The hydrogels we produced were macroscopic and strong enough to keep their shape after casting or even being handled with tweezers, thus they are true gels. For SPM, the lowest concentration that still produced a true gel was $0.40 \mathrm{w}-\%$ and for SPD the limit was $1.25 \mathrm{w}-\%$. Lower concentrations produced weak gels that still pass the tube tilt test but flow under stress. When increasing the crosslinker concentration, a non-transparent (cloudy) area is formed inside the gel due to too rapid crosslinking and uneven mixing. This effect corresponds to highly anisotropic hydrogel formation, so the appearance of the cloudy area was considered to indicate the upper limit of the crosslinker concentration. For SPM, this limit was $1.10 \mathrm{w}-\%$, and for SPD, it was $3.00 \mathrm{w}-\%$. These concentration limitations also limit the mechanical properties of produced hydrogels, as they are 
directly proportional to the crosslinker concentration, as shown in figure 4 . The same bioamine crosslinking method could be used as an alternative to many hydrogels conventionally formed with ionotropic crosslinking, for example, alginate [30], pectin [13], xanthan gum [13] and other anionic polysaccharides.

\subsection{Mechanical and rheological properties of GG bioamine hydrogel}

One design basis in current TE scaffold development is to produce biomimicking materials with mechanical properties similar to the corresponding tissue $[4 ; 6 ; 10-12]$. For the applications requiring higher stiffness (compressive or Young's modulus), such as cartilage TE, suitable GG compositions already exist [53]. For lower stiffness applications such as neural TE, however, GG needs to be modified further [17; 18]. The comparison of hydrogel properties with tissue properties would be easier if a higher consensus or standardization of the mechanical testing of biomedical samples existed, as also discussed by others [54; 55]. The lack of standardization and lack of accepted mathematical models causes high variability and difficulties in interpretation of results between different studies. To overcome this challenge, we included rabbit brain tissue samples and tested them with the same parameters as the hydrogels. According to the measurements, GG 0.40\%SPM and GG 1.25\%SPD gels with 2.7 and $9.4 \mathrm{kPa}$ modulus, respectively, most closely resembled the compression moduli of rabbit cortical brain samples at $6.3 \mathrm{kPa}$. These values are slightly higher than those often measured for the brain, with previously reported values being $0.5-3 \mathrm{kPa}[56 ; 57]$.

The hydrogel's fracture strength and strain are not comparable to brain tissue because no clear fracture point was seen on the brain samples, which underwent only a continuous strain hardening effect. In the biologically relevant deformation range of $<20 \%$ strain, the mechanical behavior is similar between bioamine GG and brain. The compression rate, however, has a direct effect on gel fracture due to the visco-elastic recovery, as elegantly shown for GG already before [58]. Based on their methodology, we chose the compression rate at a relevant range for our application. In general, our results were in line with 
those of others [58], showing that higher crosslinker concentration or faster compression rate made GG more brittle (data not shown).

Rotational rheometry was used here as a complementary method to compression testing to gain additional insight into viscoelastic properties of the hydrogels. In addition, rheometry is very sensitive to anisotropy of the measured samples; the rheological spectrum is not continuous if the material is not isotropic. This effect makes the measurements more laborious to perform, but it can also be used as a quality control for checking the similarity of parallel samples. The measurements show that all the successfully measured samples had a gel-like response [13; 59]. In the rheological spectra, the gel storage modulus was always higher than the loss modulus, in both amplitude and frequency sweep, and a fracture was seen under high strain. The rheological spectrum is also in a similar range as previously reported for GG hydrogels [26]. The high precision of rotational rheometry revealed the anisotropic nature of SPD crosslinked gels, causing those measurements to fail, but anisotropy was not discerned in compression testing. However, in cell culture, these anisotropies and nanotopographical variations can actually provide better cell anchoring sites than a totally homogenous hydrogel network [11].

\subsection{Suitability of $G G$ as a culturing matrix for human neuronal cells}

Cytocompatibility, the cellular scale response, needs to be evaluated with human cells before large-scale systemic biocompatibility testing [8]. In this work, we used hPSC-derived neuronal cells [50] to study both cytocompability and cell type-specific behavior in developed GGs. Importantly, when aiming for clinical applications, the development of neural TE products requires the usage of human cells already in the preclinical stage [60].

In this study, we used three steps to evaluate the hydrogel performance: 1) culturing cells beneath, 2) on top of or 3) encapsulated inside the hydrogel. This evaluation protocol gives information of cell survival, cell migration, and 3D network formation, but the different approaches should not be directly compared between each other [5]. First, performing the crosslinking directly on top of a pre-cultured neuronal network can reveal acute cytotoxicity caused by gel components or gelation during the first days in 
contact with the material $[5 ; 61]$. Crosslinking of GG with SPD or SPM did not cause acute (data not shown) or long-term cytotoxicity during 2-week follow-up. This result is in line with previous cytotoxicity studies for GGs $[16 ; 17 ; 20 ; 35]$. Importantly, SPD and SPM at the concentrations used for gelation (213-541 and 49.5-138 $\mu \mathrm{M}$, respectively) do not cause detrimental effects on neuronal cells. Culturing cells beneath hydrogel can also reveal gel-related effect on cell behavior, e.g., changes in cell fate as described earlier for Matrigel [61]. With GG hydrogels, no obvious changes in cell fate were observed, as these cultures developed similarly to control cultures. Successful embedding also indicates that the porosity of the developed hydrogels was sufficient for medium diffusion and metabolite exchange through the gel block (height: 2.2-2.8 mm) during 2 weeks follow up. In conclusion, bioamine crosslinked GG hydrogels provided a suitable growth environment for human neuronal cells.

To study cell type-specific behavior, we cultured human neuronal cells on top of and encapsulated in GGs. GG hydrogels are considered biologically inert materials [17]. According to earlier studies, GG does not in vitro support neuronal cell migration on top of gels or as encapsulated without the addition of cell adhesion cues $[18 ; 28]$. Our experiments using cells on top of gels showed similar results, as some neuronal aggregates remained as spheres without neurite migration as previously described for mouse neural cells [18]. Some aggregates, however, had neurite growth along the hydrogel surface. We assume that neurites growing on top of unmodified gel surfaces follow physical cues of the hydrogel. To enhance the cell migration on top of gels, we added the ECM protein laminin by physically mixing it into the GG prior to gelation. This functionalization of GG SPD hydrogels with laminin (5 v-\% to $10 \mathrm{v}-\%)$

significantly increased neurite migration. A similar positive effect was reported with fibronectin-derived synthetic GRGDS-peptide GG hydrogels [18]. Interestingly, functionalization with laminin was not beneficial with SPM crosslinked gels.

Encapsulated human neuronal cells showed a similar level of neurite migration despite functionalization with laminin. Previous studies using neural cells either on top of hydrogels or encapsulated have contradictory results about the benefits of functionalization on growth and migration. For example, functionalization with RGD, IKVAV or YIGSR peptides has shown both favorable and 
non-meaningful effects in neural cultures [62; 63]. This discrepancy could reflect the different microenvironments that cells experience in these cases.

The current paradigm of hydrogel development for TE involves making the mechanical properties mimic the tissue of interest $[4 ; 10-12]$. For neural cells, a suitable Young's modulus of hydrogel was previously reported between $1-5 \mathrm{kPa}[57 ; 64 ; 65]$. Our study revealed a wider, $2.7-22.6 \mathrm{kPa}$ range in compression moduli, enabling neuronal cell growth. At the same time, our measured compression modulus for the rabbit brain samples ranged from 7.1 to $10.1 \mathrm{kPa}$. These results strongly suggest that the lack of standardized methods produces high variability in the results, preventing valuable comparisons between studies.

Interestingly, the gels with higher compressive moduli (11.5 to $22.6 \mathrm{kPa}$ ) showed the best cell typespecific response for cells grown on top of these hydrogels; even the compressive moduli brain samples were lower $(7.1-10.1 \mathrm{kPa})$. Thus, there is a clear need to determine the actual threshold limits under which cells sense the mechanical properties of the surrounding scaffold and exhibit cell type-specific behavior [6; 12]. In other words, the true essence of biomimicking is still unknown. To answer this question, more optimal testing patterns need to be designed specifically for each tissue type. For example, the unconfined compression method measures a bulk hydrogel, whereas locally varying modulus and density, which are measurable with atomic force microscopy (AFM), are likely more important for cells [11; 12]. Compression testing should be used only to define the correct range of operations and for screening purposes, not to make specific interpretations. Although they are easier to measure and interpret, the mechanical properties of a bulk hydrogel may not be optimal to predict the cellular level response to the hydrogel. 


\section{Conclusions}

We conclude that GG hydrogels crosslinked with either SPM or SPD are cytocompatible and provide a compatible 3D scaffold for human neuronal cells. Metallic cations can be replaced by these small bioamines as ionotropic crosslinking agents. The mechanical properties of the GG bioamine hydrogel show a direct proportionality to crosslinker concentration, increasing the predictability of the properties of a certain composition. Mechanically, the GG bioamine hydrogels closely resemble the naïve rabbit brain. Both SPM and SPD crosslinked hydrogels were supporting the migration of neuronal cultures either on top of the hydrogel or as encapsulated inside the hydrogel and from a practical point of view there was no difference in gel handling between the crosslinkers. Neuronal cells grown on top of the SPD crosslinked GG hydrogels clearly benefit from laminin functionalization of the gel in a concentration dependent manner, suggesting that GG itself is too inert material for consistent neurite outgrowth. Based on our results the GG 3.00\%SPD hydrogels were the most supportive for 3D neuronal network formation inside the hydrogel, being the most promising gel composition for further studies. 


\section{Acknowledgments}

We thank Outi Paloheimo, M.Sc. from BioMediTech Imaging Core, University of Tampere, for help with microscopy of 3D cell cultures. We also thank Mari Hämäläinen, PhD from Tampere University Medical School for providing the rabbit brain samples. The study was financially supported by the Human Spare Parts program of Tekes - Finnish Funding Agency for Innovation, by the Finnish Cultural Foundation, grant numbers 00140325 and 00150312 and by the Academy of Finland grant number 286990. 


\section{References}

[1] Langer R and Vacanti J 1993 Tissue engineering. Science 260 pp. 920-926.

[2] Schmidt C E and Leach JB 2003 Neural tissue engineering: Strategies for repair and regeneration. Annu Rev Biomed Eng 5 pp. 293-347.

[3] Slaughter B V, Khurshid SS, Fisher OZ, Khademhosseini A and Peppas NA 2009 Hydrogels in regenerative medicine. Adv Mater 21 pp. 3307-3329.

[4] Nisbet D R, Crompton KE, Horne MK, Finkelstein DI and Forsythe JS 2008 Neural tissue engineering of the CNS using hydrogels. J Biomed Mater Res Part B Appl Biomater 87B pp. 251-263.

[5] Ylä-Outinen L, Joki T, Varjola M, Skottman H and Narkilahti S 2012 Three-dimensional growth matrix for human embryonic stem cell-derived neuronal cells. J Tissue Eng Regen Med $\mathbf{8}$ pp. 186-187194.

[6] Asthana A and Kisaalita WS 2013 Biophysical microenvironment and 3D culture physiological relevance. Drug Discov Today 18 pp. 533-540.

[7] Annabi N, Tamayol A, Uquillas JA, Akbari M, Bertassoni LE, Cha C, Camci-Unal G, Dokmeci MR, Peppas NA and Khademhosseini A 2014 25th anniversary article: Rational design and applications of hydrogels in regenerative medicine. Adv Mater 26 pp. 85-124.

[8] Williams D F 2008 On the mechanisms of biocompatibility. Biomaterials 29 pp. 2941-2953.

[9] Vert M, Doi Y, Hellwich K, Hess M, Hodge P, Kubisa P, Rinaudo M and Schué F 2012 Terminology for biorelated polymers and applications (IUPAC recommendations 2012). Pure Appl Chem 84 pp. 377378-410.

[10] Brandl F, Sommer F and Goepferich A 2007 Rational design of hydrogels for tissue engineering: Impact of physical factors on cell behavior. Biomaterials 28 pp. 134-146.

[11] Walters N J and Gentleman E 2015 Evolving insights in cell-matrix interactions: Elucidating how non-soluble properties of the extracellular niche direct stem cell fate. Acta Biomater 11 pp. 3-16.

[12] Ihalainen T O, Aires L, Herzog FA, Schwartlander R, Moeller J and Vogel V 2015 Differential basal-to-apical accessibility of lamin $\mathrm{A} / \mathrm{C}$ epitopes in the nuclear lamina regulated by changes in cytoskeletal tension. Nat Mater advance online publication.

[13] Morris E R, Nishinari K and Rinaudo M 2012 Gelation of gellan - A review. Food Hydrocoll 28 pp. 373-411.

[14] CP Kelco. Gellan gum | CP Kelco. 2014. Accessed 12/9, 2014. Available at:

http://cpkelco.com/products/gellan-gum/. 
[15] Fialho A M, Moreira LM, Granja AT, Popescu AO, Hoffmann K and Sá-Correia I 2008 Occurrence, production, and applications of gellan: Current state and perspectives. Appl Microbiol Biotechnol 79 pp. 889-900.

[16] Smith A M, Shelton RM, Perrie Y and Harris JJ 2007 An initial evaluation of gellan gum as a material for tissue engineering applications. J Biomater Appl 22 pp. 241-254.

[17] Ferris C J, Gilmore KJ, Wallace GG and in het Panhuis M 2013 Modified gellan gum hydrogels for tissue engineering applications. Soft Matter 9 pp. 3705-3711.

[18] Silva N A, Cooke MJ, Tam RY, Sousa N, Salgado AJ, Reis RL and Shoichet MS 2012 The effects of peptide modified gellan gum and olfactory ensheathing glia cells on neural stem/progenitor cell fate. Biomaterials 33 pp. 6345-6354.

[19] Barbani N, Guerra G, Cristallini C, Urciuoli P, Avvisati R, Sala A and Rosellini E 2012 Hydroxyapatite/gelatin/gellan sponges as nanocomposite scaffolds for bone reconstruction. J Mater Sci Mater Med 23 pp. 51-61.

[20] Oliveira J T, Martins L, Picciochi R, Malafaya PB, Sousa RA, Neves NM, Mano JF and Reis RL 2010 Gellan gum: A new biomaterial for cartilage tissue engineering applications. J Biomed Mater Res Part A 93A pp. 852-863.

[21] Lee H, Fisher S, Kallos MS and Hunter CJ 2011 Optimizing gelling parameters of gellan gum for fibrocartilage tissue engineering. J Biomed Mater Res Part B Appl Biomater 98B pp. 238-245.

[22] Shin H, Olsen BD and Khademhosseini A 2012 The mechanical properties and cytotoxicity of cellladen double-network hydrogels based on photocrosslinkable gelatin and gellan gum biomacromolecules. Biomaterials $\mathbf{3 3}$ pp. 3143-3152.

[23] Silva N A, Salgado AJ, Sousa RA, Oliveira JT, Pedro AJ, Leite-Almeida H, Cerqueira R, Almeida A, Mastronardi F, Mano JF, et al 2010 Development and characterization of a novel hybrid tissue engineering--based scaffold for spinal cord injury repair. Tissue Eng Part A 16 pp. 45-54.

[24] Pereira D R, Silva-Correia J, Caridade SG, Oliveira JT, Sousa RA, Salgado AJ, Oliveira JM, Mano JF, Sousa N and Reis RL 2011 Development of gellan gum-based microparticles/hydrogel matrices for application in the intervertebral disc regeneration. Tissue Eng Part C Methods 17 pp. 961-972.

[25] Silva-Correia J, Oliveira JM, Caridade SG, Oliveira JT, Sousa RA, Mano JF and Reis RL 2011 Gellan gum-based hydrogels for intervertebral disc tissue-engineering applications. J Tissue Eng Regen Med 5 pp. e97-e107.

[26] Silva-Correia J, Gloria A, Oliveira MB, Mano JF, Oliveira JM, Ambrosio L and Reis RL 2013 Rheological and mechanical properties of acellular and cell-laden methacrylated gellan gum hydrogels. $J$ Biomed Mater Res Part A 101 pp. 3438-3446.

[27] Tsaryk R, Silva-Correia J, Oliveira JM, Unger RE, Landes C, Brochhausen C, Ghanaati S, Reis RL and Kirkpatrick CJ 2014 Biological performance of cell-encapsulated methacrylated gellan gum-based hydrogels for nucleus pulposus regeneration. J Tissue Eng Regen Med . 
[28] Lozano R, Stevens L, Thompson BC, Gilmore KJ, Gorkin III R, Stewart EM, in het Panhuis M, Romero-Ortega M and Wallace GG 2015 3D printing of layered brain-like structures using peptide modified gellan gum substrates. Biomaterials 67 pp. 264-273.

[29] Coutinho D F, Sant SV, Shin H, Oliveira JT, Gomes ME, Neves NM, Khademhosseini A and Reis RL 2010 Modified gellan gum hydrogels with tunable physical and mechanical properties. Biomaterials 31 pp. 7494-7502.

[30] Lee C, Shin J, Lee JS, Byun E, Ryu JH, Um SH, Kim D, Lee H and Cho S 2013 Bioinspired, calcium-free alginate hydrogels with tunable physical and mechanical properties and improved biocompatibility. Biomacromolecules 14 pp. 2004-2013.

[31] Fedorovich N E, Oudshoorn MH, van Geemen D, Hennink WE, Alblas J and Dhert WJA 2009 The effect of photopolymerization on stem cells embedded in hydrogels. Biomaterials 30 pp. 344-353.

[32] Hennink W E and van Nostrum C 2002 Novel crosslinking methods to design hydrogels. Adv Drug Deliv Rev 54 pp. 13-36.

[33] Ifkovits J L and Burdick JA 2007 Review: Photopolymerizable and degradable biomaterials for tissue engineering applications. Tissue Eng 13 pp. 2369-2385.

[34] Parraga J E, Zorzi GK, Diebold Y, Seijo B and Sanchez A 2014 Nanoparticles based on naturallyoccurring biopolymers as versatile delivery platforms for delicate bioactive molecules: An application for ocular gene silencing. Int J Pharm 477 pp. 12-20.

[35] López-Cebral R, Paolicelli P, Romero-Caamaño V, Seijo B, Casadei MA and Sanchez A 2013 Spermidine-cross-linked hydrogels as novel potential platforms for pharmaceutical applications. J Pharm Sci 102 pp. 2632-2643.

[36] Soto A M, Koivisto JT, Parraga JE, Silva-Correia J, Oliveira JM, Reis RL, Kellomäki M, Hyttinen J and Figueiras E 2016 Optical projection tomography technique for image texture and mass transport studies in hydrogels based on gellan gum. Langmuir 32 pp. 5173-5182.

[37] Khan A U, Mei YH and Wilson T 1992 A proposed function for spermine and spermidine:

Protection of replicating DNA against damage by singlet oxygen. Proc Natl Acad Sci 89 pp. 11426 11427.

[38] Ha H C, Sirisoma NS, Kuppusamy P, Zweier JL, Woster PM and Casero RA,Jr 1998 The natural polyamine spermine functions directly as a free radical scavenger. Proc Natl Acad Sci U S A 95 pp. 11140-11145.

[39] Fujiwara K, Bai G and Kitagawa T 1997 Polyamine-like immunoreactivity in rat neurons. Brain Res 767 pp. 166-171.

[40] Laube G, Bernstein H, Wolf G and Veh RW 2002 Differential distribution of spermidine/sperminelike immunoreactivity in neurons of the adult rat brain. J Comp Neurol 444 pp. 369-386.

[41] ASTM F2900 2011 Standard Guide for Characterization of Hydrogels used in Regenerative Medicine (West Conchoken, PA, USA: ASTM International) pp.1-10. 
[42] Tanodekaew S, Godward J, Heatley F and Booth C 1997 Gelation of aqueous solutions of diblock copolymers of ethylene oxide and D,L-lactide. Macromol Chem Phys 198 pp. 3385-3395.

[43] Callister W D 2003 Materials Science and Engineering: An Introduction (New York, NY, USA: John Wiley \& Sons) pp.117-120, 480-498.

[44] Schramm G 1998 A Practical Approach to Rheology and Rheometry (Karlsruhe, Germany: Gebrueder HAAKE GmbH) pp.119-133.

[45] Rajala K, Lindroos B, Hussein SM, Lappalainen RS, Pekkanen-Mattila M, Inzunza J, Rozell B, Miettinen S, Narkilahti S, Kerkelä E, et al 2010 A defined and xeno-free culture method enabling the establishment of clinical-grade human embryonic, induced pluripotent and adipose stem cells. PLoS One 5 pp. e10246.

[46] Skottman H 2010 Derivation and characterization of three new human embryonic stem cell lines in finland. In Vitro Cell Dev -An 46 pp. 206-209.

[47] Sorkio A E, Vuorimaa-Laukkanen EP, Hakola HM, Liang H, Ujula TA, Valle-Delgado JJ, Österberg M, Yliperttula ML and Skottman H 2015 Biomimetic collagen I and IV double layer Langmuir-Schaefer films as microenvironment for human pluripotent stem cell derived retinal pigment epithelial cells. Biomaterials 51 pp. 257-269.

[48] Ojala M, Prajapati C, Pölönen R, Rajala K, Pekkanen-Mattila M, Rasku J, Larsson K and AaltoSetälä K 2016 Mutation-specific phenotypes in hiPSC-derived cardiomyocytes carrying either myosinbinding protein $\mathrm{C}$ or $\alpha$-tropomyosin mutation for hypertrophic cardiomyopathy. Stem Cells Int $\mathbf{2 0 1 6} \mathrm{pp}$. 16.

[49] Toivonen S, Ojala M, Hyysalo A, Ilmarinen T, Rajala K, Pekkanen-Mattila M, Äänismaa R, Lundin K, Palgi J, Weltner J, et al 2013 Comparative analysis of targeted differentiation of human induced pluripotent stem cells (hiPSCs) and human embryonic stem cells reveals variability associated with incomplete transgene silencing in retrovirally derived hiPSC lines. Stem Cells Transl Med 2 pp. 83-93.

[50] Lappalainen R S, Salomäki M, Ylä-Outinen L, Heikkilä TJ, Hyttinen JAK, Pihlajamäki H, Suuronen R, Skottman H and Narkilahti S 2010 Similarly derived and cultured hESC lines show variation in their developmental potential towards neuronal cells in long-term culture. Regener Med 5 pp. 749-762.

[51] Rasband WS. ImageJ. 2016. Accessed 05/11, 2016. Available at: http://imagej.nih.gov/ij/.

[52] Schneider C A, Rasband WS and Eliceiri KW 2012 NIH image to ImageJ: 25 years of image analysis. Nat Meth 9 pp. 671-675.

[53] Oliveira J T, Santos TC, Martins L, Picciochi R, Marques AP, Castro AG, Neves NM, Mano JF and Reis RL 2010 Gellan gum injectable hydrogels for cartilage tissue engineering applications: In vitro studies and preliminary in vivo evaluation. Tissue Eng Part A 16 pp. 343-353.

[54] Oyen M L 2014 Mechanical characterisation of hydrogel materials. Int Mater Rev 59 pp. 44-59.

[55] Prevost T P, Balakrishnan A, Suresh S and Socrate S 2011 Biomechanics of brain tissue. Acta Biomater 7 pp. 83-95. 
[56] Laksari K, Shafieian M and Darvish K 2012 Constitutive model for brain tissue under finite compression. J Biomech 45 pp. 642-646.

[57] Engler A J, Sen S, Sweeney HL and Discher DE 2006 Matrix elasticity directs stem cell lineage specification. Cell 126 pp. 677-689.

[58] Nakamura K, Shinoda E and Tokita M 2001 The influence of compression velocity on strength and structure for gellan gels. Food Hydrocoll 15 pp. 247-252.

[59] Kavanagh G M and Ross-Murphy SB 1998 Rheological characterisation of polymer gels. Prog Polym Sci 23 pp. 533-562.

[60] Lindvall O and Kokaia Z 2010 Stem cells in human neurodegenerative disorders - time for clinical translation? J Clin Invest 120 pp. 29-40.

[61] Thonhoff J R, Lou DI, Jordan PM, Zhao X and Wu P 2008 Compatibility of human fetal neural stem cells with hydrogel biomaterials in vitro. Brain Res 1187 pp. 42-51.

[62] Zhang Z, Freitas BC, Qian H, Lux J, Acab A, Trujillo CA, Herai RH, Nguyen Huu VA, Wen JH, Joshi-Barr S, et al 2016 Layered hydrogels accelerate iPSC-derived neuronal maturation and reveal migration defects caused by MeCP2 dysfunction. Proc Natl Acad Sci 113 pp. 3185-3190.

[63] Frampton J P, Hynd MR, Shuler ML and Shain W 2011 Fabrication and optimization of alginate hydrogel constructs for use in 3D neural cell culture. Biomedical Materials 6 pp. 015002.

[64] Pogoda K, Chin L, Georges PC, Byfield FJ, Bucki R, Kim R, Weaver M, Wells RG, Marcinkiewicz $\mathrm{C}$ and Janmey PA 2014 Compression stiffening of brain and its effect on mechanosensing by glioma cells. New J Phys 16 pp. 075002.

[65] Palazzolo G, Broguiere N, Cenciarelli O, Dermutz H and Zenobi-Wong M 2015 Ultrasoft alginate hydrogels support long-term three-dimensional functional neuronal networks. Tissue Eng Part A 21 pp. 2177-2185. 
SUPPORTING INFORMATION

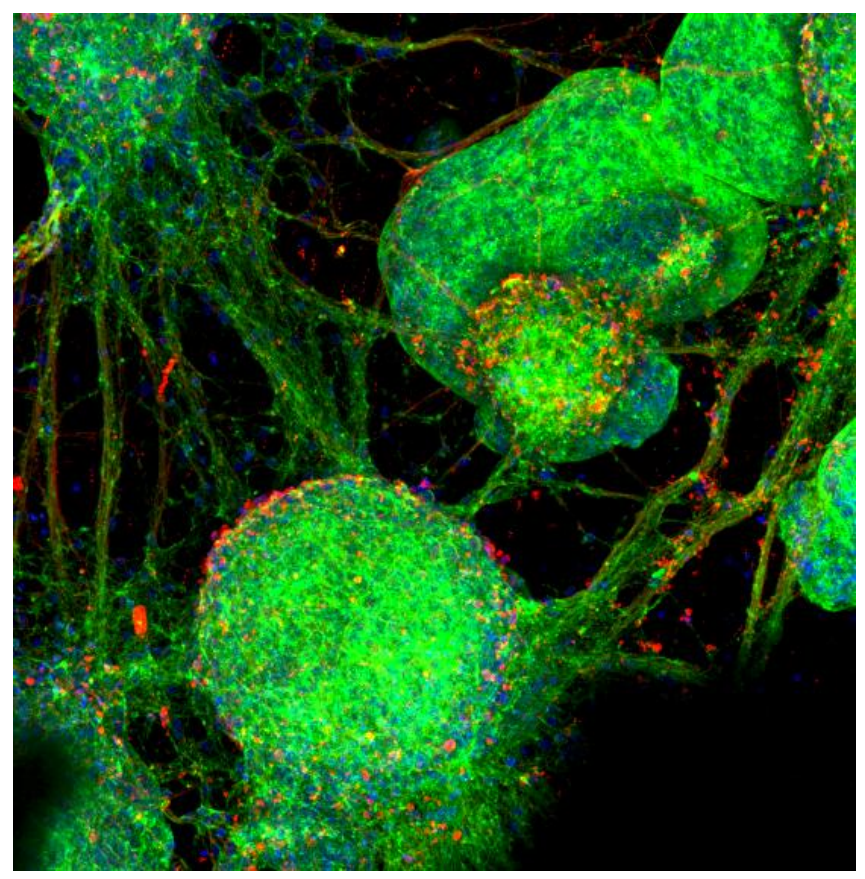

Supplementary video 1. Confocal microscope image of hPSC-derived neuronal cells cultured inside the GG hydrogel. Cells were immunostained against MAP-2+ $\beta$-tubulin ${ }_{\text {III }}$ (green), labelled with phalloidin (red) and DAPI (blue). 


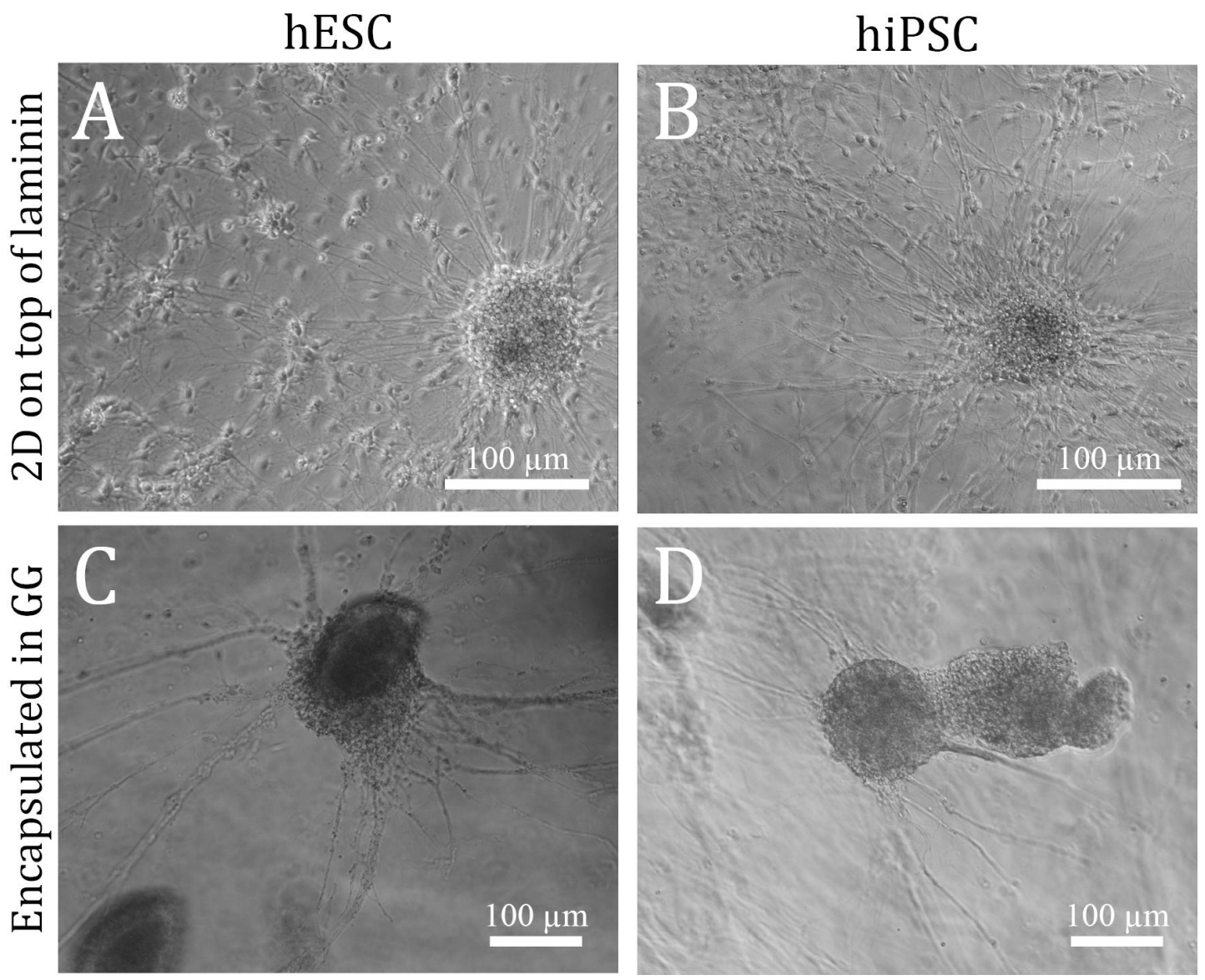

Supplementary figure 1. Phase contrast images of neuronal cultures similarly derived from hESC and hiPSC origin. Representative images of good quality 2D neuronal cultures on top of laminin coated plastic (A, B). Similarly derived neuronal cultures encapsulated inside GG hydrogel (C, D). Scale bars: $100 \mu \mathrm{m}$. 